\title{
A NEW ZERO-RIPPLE SWITCHING DC-TO-DC CONVERTER AND INTEGRATED MAGNETICS
}

\author{
SLOBODAN ĆUK \\ Californio Instifute of Technology \\ Pasadeno, California
}

\section{ABSTRACT}

A new switching dc-to-dc converter is synthesized which consists of the least number of storage elements (inductive and capacitive) and switches, and yet truly emulates the ideally desired dc-to-dc transformer having both input and output currents as pure dc quantities with no ripple. This result was facilitated by implementation of a new concept termed integrated magnetics, which leads in some special switching structures to the integration of otherwise independent and separate magnetic components linductors and transformers I into a single magnetic circuit.

\section{INTRODUCTION}

Virtually any electronic or electrical equipment has some form of dc power requirements, often at multiple dc voltage and current levels. The area of dc-to-dc power conversion therefore constitutes a major part of the Power Electronics field.

The physical impossibility of a magnetic dcto-dc transformer has led to indirect or alternative ways of achieving the same function through the process of switched-mode power conversion.

a)
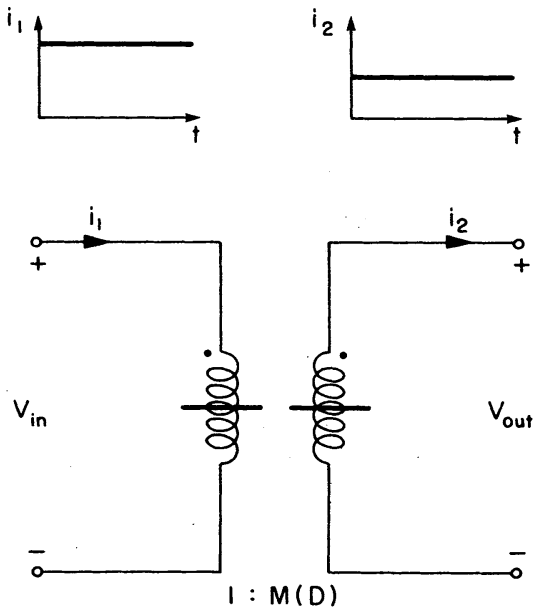

An input dc voltage is first converted to ac through some switching mechanism, ac power is processed through the usual ac transformer and finally, by some effective low-pass filtering, the output dc voltage is recovered. However, while this voltage conversion approaches the ideally desired one, except for the ever-present switching ripple voltage at the output, the current conversion is far from the ideal one represented by constant dc input and output currents as shown in Fig. 1. In fact, some of the major problems which limit "switchers" are the large pulsating currents at either input or output or both ports of commonly used switching dc-to-dc converters, which in turn lead to severe conducted and radiated electromagnetic interference problems (EMI).

The search for inherently low noise and more efficient new switching converter topologies was initiated several years ago [1], and was originally motivated by the desire to reduce or possibly eliminate these formidable pulsating currents. The ultimate objective envisioned was to synthesize the generalized dc-to-dc transformer function with the ideal constant (dc) current waveforms shown in Fig. la, in an optimum manner, by use of the least number of switches and storage components (Fig. 1b) in order to maximize the efficiency.

b)
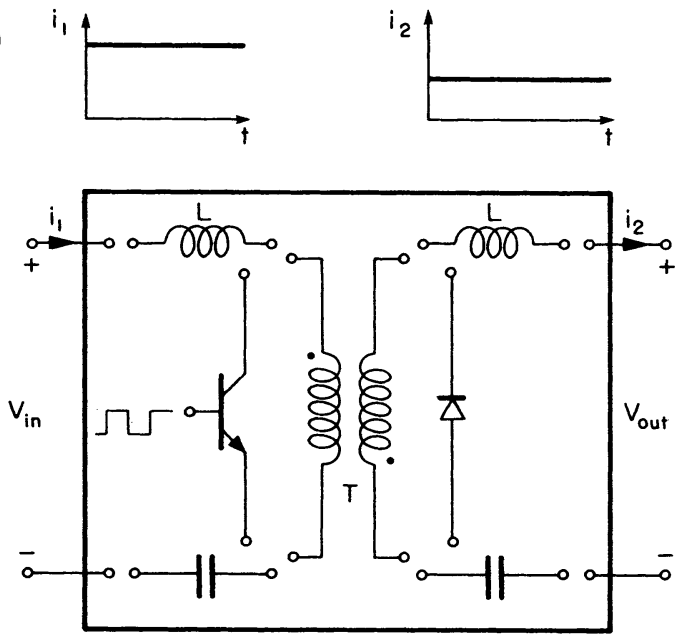

Fig. 1 The objective of $d c-t o-d c$ conversion -. the search for converter topology realized by physical hardware (b) which will approach its ideally desired goal: dc-to-dc voltage transformer (a) with de currents at both input and output.

This work was sponsored in part by the Office of Naval Research, Washington, DC, under the contract N00014-78-C-0757, by the Naval Ocean Systems Center, San Diego, CA, contract N66001-78-C-0351 JAP, and by the International Business Machines Corporation, Kingston, NY. 
Unlike some other approaches in which the emphasis is on the switching mechanism only [20], and the filtering is added after the fact to "clean up" input and output current or voltage waveforms, we have considered storage elements (inductors, transformer and capacitors) together with the switches as an integral part of the overall problem, as shown by the block diagram of Fig. 1b. Furthermore, the utmost importance is attached to the topology of the component interconnection. In Fig. $1 \mathrm{~b}$, for example, both minimum component selection, topology of their electrical connection and, considered here for the first time, the topology of the magnetic connections, has yet to be determined in order to emulate the ideally desired generalized dc-to-dc transformer of Fig. 1a. The problem at first may seem formidable, but with some background material covered in Section 2, and the grasp of the generality of the coupled-inductor method in Section 3 , the contours of the solution will begin to appear.

The first major step in that direction was the invention of a new optimum topology (Ćuk) converter, which has substantially reduced conducted EMI problems by creating nonpulsating input and output currents (average dc currents with superimposed triangular ripple currents). Both the basic Cuk converter and its dc isolated version are briefly reviewed in Section 2, since they constitute the major building blocks for the subsequent development.

Although originated from the investigation of the unique topology of the Cuk converter, coupling of inductances in switching structures is shown in Section 3 to be a powerful new concept. It not only leads to converter ripple current improvement (with even the possibility of zero ripple current at one end) but, in addition, has the potential for further reduction in size, weight, and losses of the magnetic content of switching structures, as investigated in Section 3. From the conceptual viewpoint, it is recognized in Section 3 that the coupled-inductor extension of the Cuk converter represents the first time that the two magnetic components (inductors), which are normally and exclusively used separately to perform their function, have been integrated into a single magnetic circuit with two windings.

The recognition of these facts leads in Section 4 to the search for switching configurations in which such integration can be achieved at an even higher level, by incorporating both separate inductors and ac transformers into a single magnetic circuit, with addiontal size and weight reduction and performance improvement (ripple current reduction and increase of efficiency). A number of zero-ripple switching converter configurations are introduced, featuring both isolated and nonisolated extensions. Finally, Section 4 is concluded with some multiple output extensions.

Fundamental practical verification of zerocurrent ripple is made in Section 5 through several experiments.
The new and general method which emerges as a natural outgrowth of the coupled-inductor concept is termed the integrated magnetics concept in clear analogy with the integrated semiconductor terminology, as is justified in Section 6, where this general method is postulated. A number of its applications to other switching dc-to-dc converters as well as to functionally different switching dcto-ac inverters such as the Cuk amplifier is shown to lead to similar improvements.

Finally in Section 7, a survey of the family of new converter configurations is made, featuring their key topologies.

Thus, this paper describes the culmination of research along two fundamental lines developed in parallel: the first is a practical line which is concerned with synthesis of useful new converter/ inverter configurations, and the second is a theoretical one which deals with new concepts of general applicability to switching structures.

\section{$\frac{\text { 2. REVIEW OF THE BASIC CUK CONVERTER AND ITS DC }}{\text { ISOLATED EXTENSION }}$}

The hardware implementation of the new converter using a transistor/diode combination to implement the ideal single-pole double-throw switch is shown in Fig. 2. With the transistor off (open), $C_{1}$ is charged by, the input current through the forward-biased diode. When the transistor turns on, the voltage on capacitance $C_{1}$ reverse-biases the diode, turning it of $f$, and the previously stored charge on $\mathrm{C}_{1}$ is discharged through the transistor to the load. Thus, capacitive energy transfer in this converter is fundamental to its operation just as inductive energy transfer is essential for operation of the three basic converter types (buck, boost, and buck-boost). The presence of the two inductors in series with the input and output ports, respectively, leads to one of its important distinguishing features--nonpulsating input and output currents--as seen in Fig. 2.

NEW SWITCHING DC-TO-DC CONVERTER

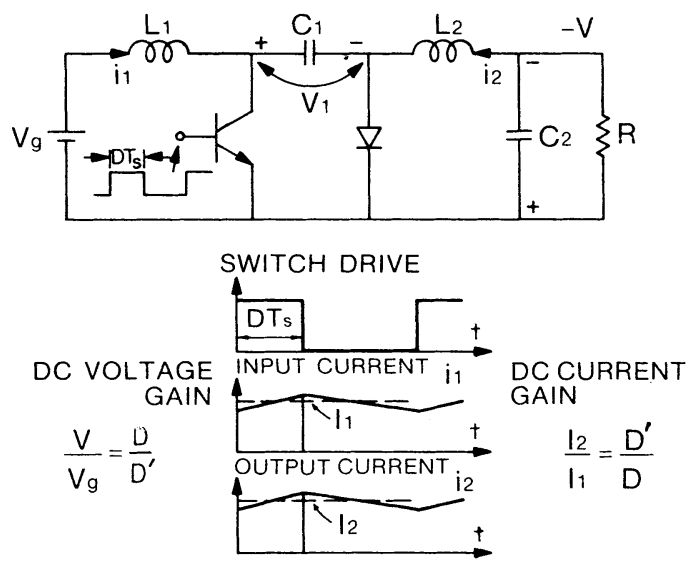

Fig. 2 The basic Cuk converter features nonpulsating input and output currents in the simplest topology. 
The important dc isolation feature, very often required in practice, can easily be introduced in an "optimum manner" following the three key steps illustrated in Fig. 3. The first step is to separate the coupling capacitance into two series capacitances $C_{a}$ and $C_{b}$, and thus to make the original symmetrical configuration divisible into two halves; each one is a mirror image of the other, as seen in Fig. 3a. The second step is to recognize that the connection point between these two capacitances has an indeterminate dc voltage. This indeterminate voltage can then be set at zero, by placing an inductance between this point and ground, as shown in Fig. 3b. The third and final step is merely the separation of the extra inductance into two equal transformer windings, which thus provide the desired dc isolation between input and output as illustrated in Fig. 3c. Dc isolation obtained in this way not only has some outstanding features when compared to other popular isolated switching structures [4], but also has preserved completely the overall features of the basic converter. Thus some other important extensions applicable to the basic converter configuration are equally applicable as shown next, to its isolated version.
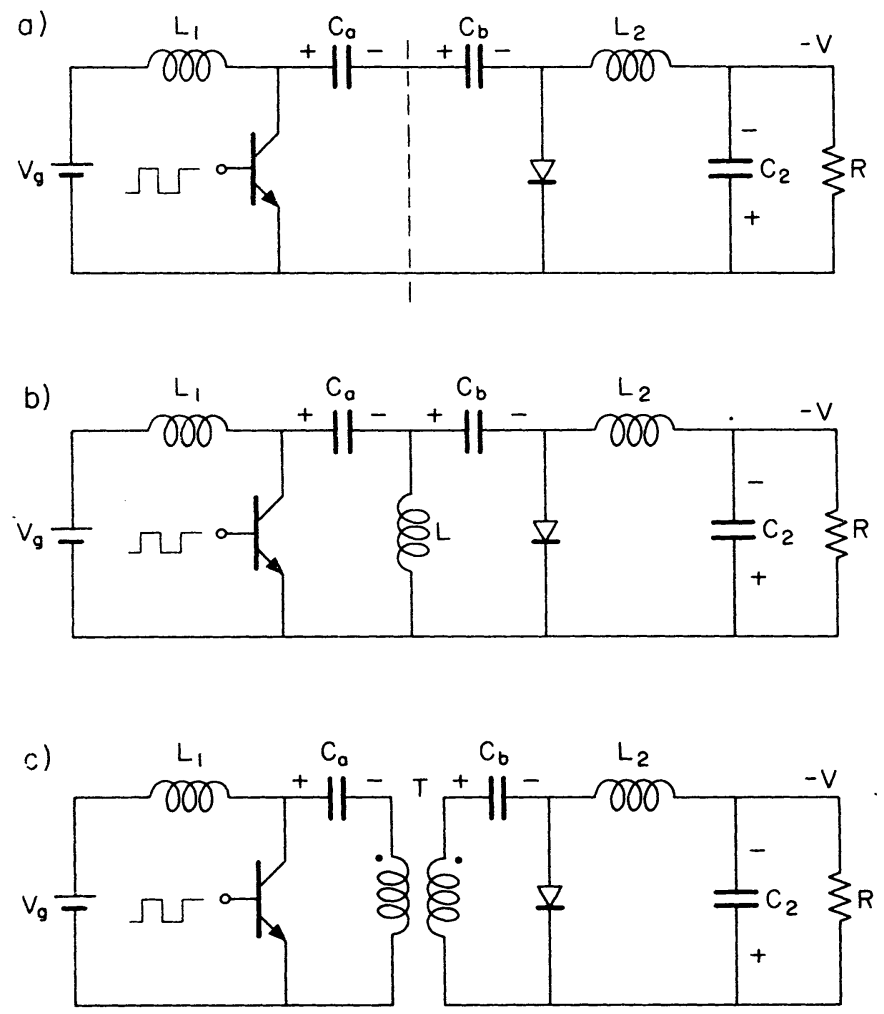

Fig. 3 Three key steps leading to the dc isolation in the original cuk converter.

\section{COUPLED-INDUCTOR METHOD}

It would seem from the above exposition that the simplest possible converter circuit has been obtained in the form of the basic Cuk converter (Fig. 2), but this is not the case. Consideration of the voltage waveforms across the two inductors $\mathrm{L}_{1}$ and $\mathrm{L}_{2}$ over the switching cycle reveals that, for the average dc voltage across each inductor to be zero, (steady-state condition, the so-called volt-second balance on inductors), the two waveforms must be identical, as seen in Fig. 4. This direct $1: 1$ proportionality of the inductor voltage waveforms was the original motivation for coupling the two inductors by putting them on the same core. What is obtained appears to resemble a conventional ac transformer, at least as far as the customary symbol for an ac transformer suggests in the converter of Fig. 5. However, it becomes rather quickly obvious that it is a quite peculiar kind of transformer, since it must pass the dc current at both primary (average input inductor current) and secondary (average output inductor current). Furthermore, for the polarity marks (dots) as shown in Fig. 5, secondary current $i_{2}$ is flowing into the dot terminal, rather than in the opposite direction as it would for a conventional ac transformer, where the dot designates positive voltage polarities.
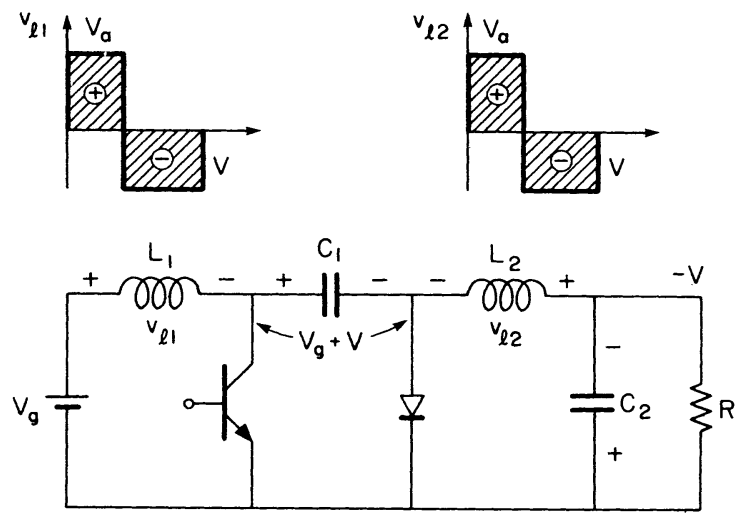

Fig. 4 observation of the proportional $[1: 1]$ inductor voltage waveforms leads to a new concept of coupling inductors.

Any conceptual difficulties raised by this are easily removed by observing that it is a coupled-inductor structure. Only the ac properties are affected by this coupling method, and not the basic dc conversion properties which remain the same as before the coupling. Hence the converter configuration in Fig. 5 is a perfectly valid switching configuration, and deserves closer examination, particularly as far as its ac or inductor ripple current properties are concerned. However, before going into detailed analysis, let us make one important observation. 


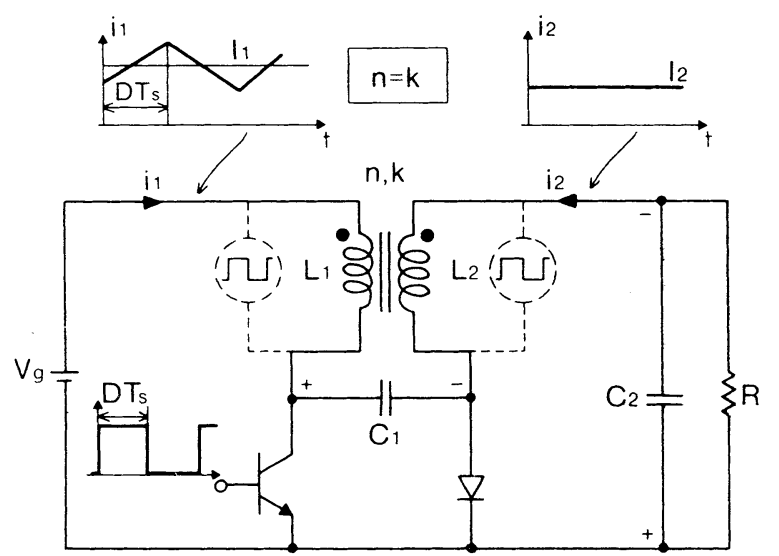

Fig. 5 Coupling of the inductors in the basic 'uk converter results in this switc' ing converter.

The coupled-inductor extension of the optimum topology (cuk) converter represents the first time that the two magnetic components (inductors), which are nominally and exclusively used separately to perform their function, have been integrated into a single magnetic circuit with two windings. This single magnetic circuit still preserves the original two inductive functions, but alters their effective values.

In addition to the original capacitive energy transfer between input and output ports, the inductor coupling brings in a simultaneous inductive energy transfer. Thus one may intuitively feel that this coupling method will lead to reduced ripple currents at both input and output, which is indeed the case. The quantitative aspect of the current ripple reduction can easily be analyzed from the subset of the original converter in Fig. 5 , featuring the coupled-inductor equivalent circuit model excited by proportional voltage waveforms on both primary and secondary side, as illustrated in Fig. 6c. Note that the equivalent circuit model of the coupled-inductors is identical with the familiar T-model of the usual ac transformer, featuring leakage inductances $\mathrm{L}_{\mathrm{p}}$ and $\mathrm{L}_{\mathrm{s}}$ and magnetizing inductance $L_{m}$, except that in this model the secondary current direction is reversed, leading to a magnetizing current $i$ which is the sum of the primary and reflected secondary current. With the help of this model several qualitatively different cases may be distinguished. Here a brief and rather simplified explanation of only two cases of interest are given, while a complete, more detailed and rigorous account can be found in [21]. Shown in dotted lines in Fig. 6 are current ripples before coupling and, in heavy lines, after coupling. The two cases considered are: balanced ripple current reduction (Fig. 6a), and the limiting zero-ripple case of the unbalanced current ripple reduction (Fig. 6b). There are many alternative ways by which coupled-inductors can be uniquely represented. One possible method is a physical a)

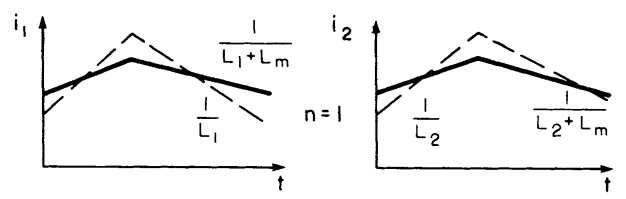

b)

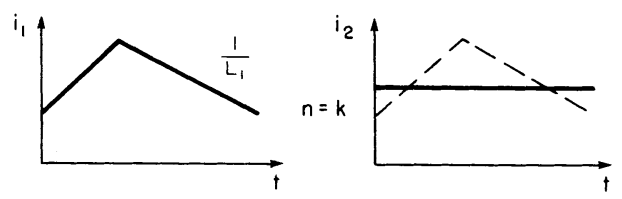

c)

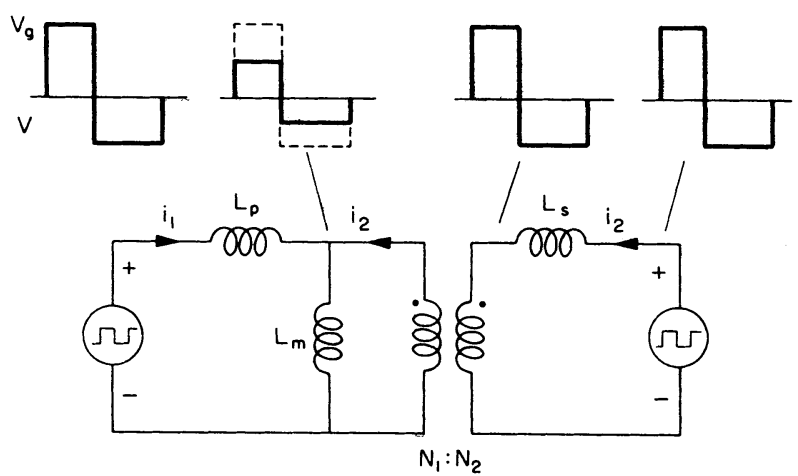

Fig. 6 Explanation of the ripple current reduction in the coupled inductor converter of Fig. 5: current ripple before coupling in dotted lines, after coupling in heavy lines.

description through primary and secondary leakage inductances $\mathrm{L}_{\text {and }} \mathrm{L}$, magnetizing inductance $\mathrm{L}$, and ideal $\mathrm{N}_{1}: \mathrm{R}_{2}$ transformer as shown in Fig. $6 .{ }^{2}$ An alternative set of three parameters is the coupling coefficient $k$, secondary self inductance $\mathrm{L}_{2}$, and effective turns ratio $\mathrm{n}$ defined by $\mathrm{n}=\sqrt{\mathrm{L}_{1} / \mathrm{L}_{2}}$.

\section{(a) Balanced ripple current reduction}

From Fig. 6c, or using coupled-inductor equations, one obtains for equal current ripples (and $\mathrm{n}=1$ ),

$$
\frac{d i_{1}}{d t}=\frac{d i_{2}}{d t}=\frac{v_{s}}{(1+k) L_{2}}
$$

Hence both current ripples are reduced by a factor $(1+k)$ from their original uncoupled yalue $(k=0)$. In the limiting case when $k$ approaches 1 (tight coupling), both current ripples are cut in half. However, this may be considered as the least beneficial improvement, since there is an even more interesting case of unbalanced reduction of current ripples. 


\section{(b) Unbalanced ripple current reduction-- zero-ripple case}

The relative change of the effective turns ratio $n$ with respect to coupling coefficient $k$ results in the steering of the current ripple from one side to the other. For the so-called matching condition

$$
\mathrm{n}=\mathrm{k}
$$

where

$$
\mathrm{n}=\sqrt{\mathrm{L}_{1} / \mathrm{L}_{2}}, \quad \mathrm{k}=\frac{\mathrm{L}_{\mathrm{M}}}{\sqrt{\mathrm{L}_{1} \mathrm{~L}_{2}}}
$$

zero current ripple is achieved in the output, as seen in Fig. 6b.

To get a better physical grasp how that is made possible, the equivalent circuit model in Fig. $6 \mathrm{c}$ is quite helpful. As seen from the accompanying waveforms, the input switched voltage waveform $v$ is attenuated by the inductive voltage divider comprised of $\mathrm{L}_{\mathrm{s}}$ and $\mathrm{L}_{\mathrm{m}}$. However, if the actual turns ratio $\mathrm{N}_{1}: \mathrm{N}_{2}$ of the ideal transformer is just right to step up this attenuated voltage to its previous value (as illustrated on the secondary of the ideal transformer), the net voltage across the secondary leakage inductance $\mathrm{L}_{\mathrm{s}}$ is zero throughout the cycle, that is $\mathrm{v}_{\mathrm{I}}=0$. Thus, since $\mathrm{L}$ is finite, it follows that $\mathrm{di}_{2} / \mathrm{dt}=0$, and the secondary current ripple is reduced to zero. The key to the process is the recognition that the coupled inductors are being driven by a (switched) voltage source $v_{\text {at }}$ ath windings, and zero ripple results from balancing the drive-related voltages that exist at the two ends of a leakage inductance. The detailed analysis reveals that the primary current ripple remains at its level before the coupling.

A change of effective turns ratio $n$ with respect to the coupling coefficient $k$ has, therefore, the role of steering the current ripple from one side to the other from its symmetrical (balanced) reduction for $n=1$, and for the matching condition $(n=k)$ results in the complete removal of current ripple from one side.

Zero-current ripple at the output has important practical ramifications for applications where switching ripple needs to be reduced as much as possible, such as the switching audio amplifier [6] or computer power supplies, for example. From the practical standpoint it is also invaluable that the zero current ripple has been demonstrated [21], to first order, to be solely a property of the coupledinductors' design. For example, interchange of the primary and secondary leads in the coupled-inductor converter of Fig. 9, results again in the zerocurrent ripple, but now on the input side. In practice, once we have designed the coupledinductor to satisfy the matching condition (2), we usually put $d c$ current side designation on the appropriate leads! Even in the face of changes of the operating point (duty ratio $\mathrm{D}$ and switching

frequency $f_{\text {f }}$ or line voltage $v_{f}$ ), the zero-ripple condition is maintained since the basic proportionality of inductor voltage waveforms still holds. Furthermore, it is not affected when the converter moves into the discontinuous conduction mode since the voltage waveforms, although more complex in shape, are still proportional [21].

The coupled-inductor method is not limited to the particular switching converter topology described, but' may be applied to other switching structures with similar benefits. For example, when applied to the straightforward cascade connection of boost and buck converters, zero current ripple can be achieved, but only in the continuous conduction mode [21]. In the discontinuous conduction mode the two inductor voltage waveforms lose proportionality [21] and the previously adjusted zero ripple is suddenly lost. The coupled-inductor method is thus a general technique and tool which can be applied to switching structures to improve their performance. From the several examples, a general law may be postulated:

In any switching structure, a number of separate inductors (two or more) can be integrated into a single magnetic circuit with multiple windings, provided the inductor voltage waveforms before coupling are in a fixed ratio of proportionality to one another.

This broadened generality of the coupledinductor concept can be easily checked on several other examples. For example, the isolation transformer was embedded into the basic nonisolated converter with the least disturbance to its mode of operation (see Fig. 3c in Section 2.) The proportionality of the input and output inductor voltage waveforms is preserved and the two inductors can again be coupled. Furthermore, if the isolation transformer has a $\mathrm{N}_{1}: \mathrm{N}_{2}$ turns ratio, the coupledinductors should be designed with the same $\mathrm{N}_{1}: \mathrm{N}_{2}$ turns ratio in order to preserve $1: 1$ proportionality of the inductor voltage waveforms, such as shown in Fig. 7. Note that the coupling capaci-

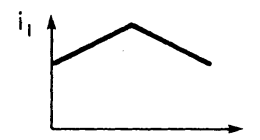

$i_{2}$

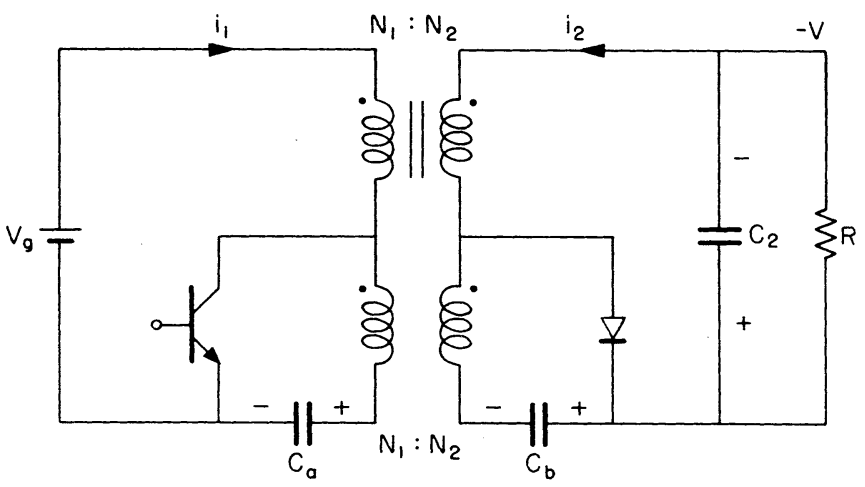

Fig. 7 Coupled-inductor dc isolated cuk converter. 
tors $C$ and $C_{6}$ are shown relocated to the other side of ${ }^{a}$ the respective primary and secondary windings, which may be beneficial in some practical applications as pointed out in [12].

The same opportunity for coupling the inductors exists in the transformer-isolated multiple-output version of the Cuk converter: any or all of the inductors can be coupled, that is, wound on the same core. The magnetic content in Fig. 8 is therefore reduced only to two magnetic "lumps": one providing the isolation, and the other supplying the inductor function at input and all the outputs. Again, by proper design of this coupled-inductor multiple winding (four in Fig. 8) the ripple currents can be steered to, or away from, the input port or any of the output ports. One of course has the choice to couple fewer than four windings on a single core. For example, it was demonstrated in $[12,13]$ that input and one of the outputs can be coupled to obtain zero current ripple on the input side, while the coupled-inductor structure obtained from the remaining two outputs can be adjusted for zero-current ripple in one of them. Hence a configuration is obtained with zero current ripple at input and selected output simultaneously.

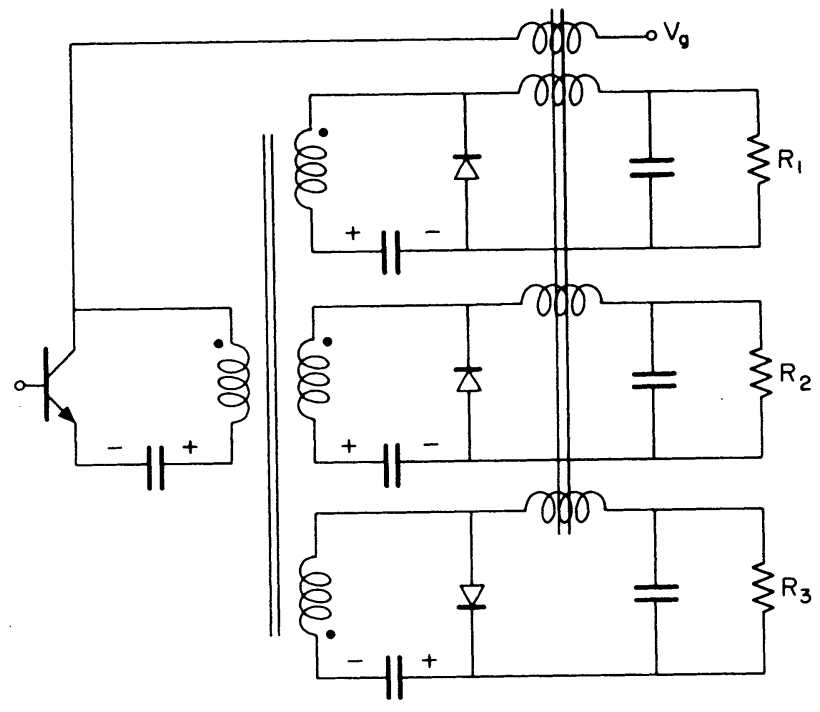

Fig. 8 Multiple output Cuk converter with only two magnetic lumps: one for the isolation transformer, and the other with input and all output inductors on the same core.

It now becomes obvious that the coupledinductor technique leads to significant ripple current improvement over its uncoupled counterpart, especially for zero-ripple design. However, it is at first less transparent how it can also lead to savings in size, weight, and reduction of losses, requirements which for many applications are at a premium.
3.1. Comparative Assessment of the Uncoupled and Coupled-Induct or Magnetic Design

So far we have concluded that if the same magnetic core material and copper materials were used to build a coupled-inductor instead of two separate inductors, substantial ripple-current reductions on both sides are possible. Let us now reverse the problem and pose the following question:

For the same given input and output ripple current performance, how much is the coupledinductor design more efficient and compact compared to the two separate inductor implementation of the switching converter?

It is apparent at the outset that the most unfavorable comparison for the coupled-inductor would be the case of equal or balanced ripple reduction (current ripple reduced in half), which we will consider here as the least beneficial case. In the other most beneficial extreme of zero ripple, one of the two separate inductors would have to be infinite, hence clearly impossible to achieve by two separate inductors.

To further simplify the comparison without impairing its generality, let us assume that each converter in Fig. 9 operates at the same operating point $\mathrm{D}=0.5$ such that input and output inductor $\mathrm{dc}$ currents are $I$. Also the inductors in the converter of Fig. 9a are assumed equal to $\mathrm{L}$, while the self-inductances of the coupled-inductor in Fig. $9 \mathrm{~b}$ are assumed to be $\mathrm{L} / 2$ (which corresponds to balanced ripple current reduction). With these assumptions, both converters exhibit the same ripple properties at both input and output ports.

Let us now compare the optimum magnetic design in the two converters for the two cases: a) considering that they have the same magnetic core material, hence, core losses will be the same, and copper losses will be compared;

b) considering that they have the same winding material, hence, their copper losses will be the same, and core losses different.

\section{(a) Comparison of copper losses for same core losses}

Suppose that the inductors for the converter in Fig. 9a are made of toroids with cross section Ac, mean magnetic path length $\ell$ and permeability $\mu$, and that in each toroid we can $\mathrm{m}_{\mathrm{it}} 2 \mathrm{~N}$ turns, as shown in Fig. 10a. The material used can be any standard one used for inductors such as powdered iron or molypermalloy which have a distributed air gap and some effective $\mu$ to describe it. The effective $\mu$ of the core is chosen to allow de bias current I without saturating the core. The inductance $\mathrm{L}$ then becomes:

$$
L=\frac{\mu 4 \mathrm{~N}^{2} \mathrm{~A} c}{\ell_{\mathrm{m}}}
$$



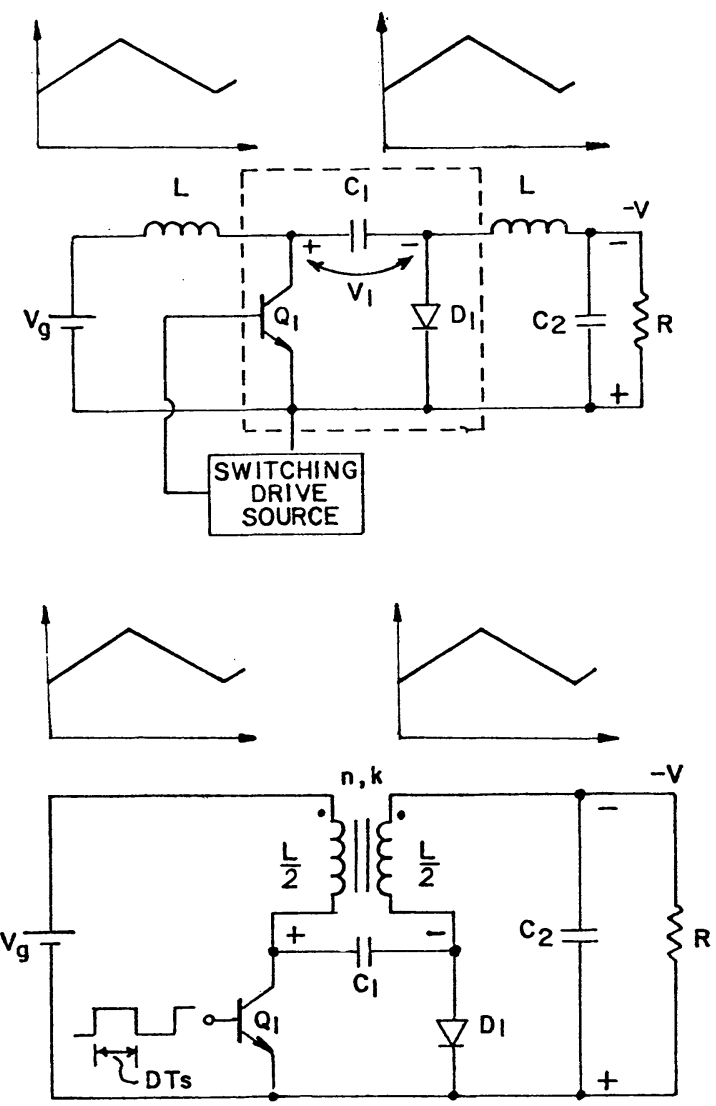

Fig. 9 Comparison of the separate inductor versus coupled-inductor design for equal ripple current performance.

Let us now stack the two cores together and build coupled-inductors with $\mathrm{N}$ turns primary and $\mathrm{N}$ turns secondary, thus again completely filling the usable winding area and making optimal use of the core as before. The self inductances of the primary and secondary now become, with twice the core area $\mathrm{A}_{\mathrm{c}}$,

$$
\mathrm{L}_{1}=\frac{\mu \mathrm{N}^{2} 2 \mathrm{~A}_{\mathrm{c}}}{\ell_{\mathrm{m}}}=\frac{\mathrm{L}}{2}
$$

Because of the mutual inductance of the order of $\mathrm{L} / 2$, the total effective input inductance is again $\mathrm{L} \mathrm{L}_{\mathrm{L}} \mathrm{L}$ and the same current ripple as before is obtained. Note also that the same maximum utilization of the dc capability of the cores is used, since in each case from Ampere's law

$$
\mathrm{H} \ell_{\mathrm{m}}=2 \mathrm{NI}
$$

Thus in both cases the same amount of core material is used. However, the savings in terms of copper losses and size and weight with coupledinductor design is quite obvious from Fig. 10a and
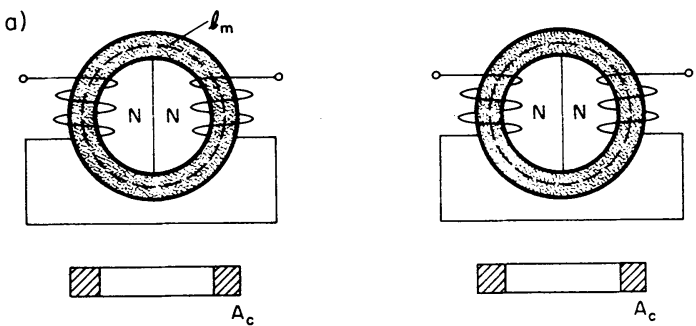

b)
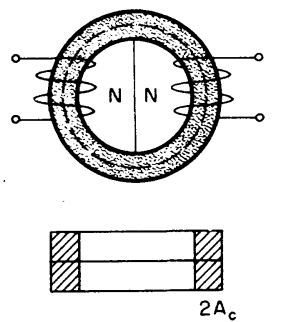

Fig. 10 Comparison of two separate inductors (a) versus coupled-inductor design (b) for the converter in Fig. 2 assuming equal core lasses.

a)

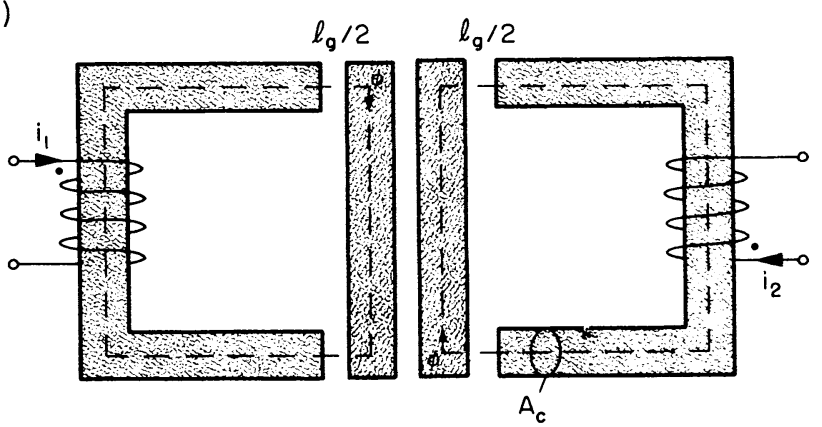

b)

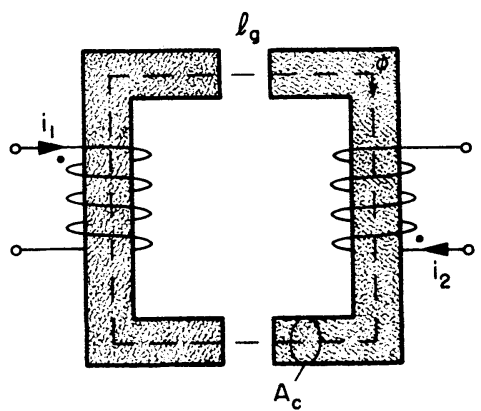

Fig. 11 Comparison of two separate inductors $(a)$ versus coupled-inductor (b) for the converter in Fig. 9. assuming equal copper losses. 
b comparison. The separate inductors result in almost doubling the copper losses, and occupying a space well above the double volume of the coupled-inductors.

\section{(b) Comparison of core losses for same copper 1osses}

We now consider the case in which the copper losses are maintained the same. Let us now take another geometrical configuration, say U-I cores as shown in Fig. 11 and core material with high $\mu$ (hard material). Then an air gap of length $\ell$ has to be inserted to give the inductance $L$ in the converter of Fig. 9a the dc current capability of $\mathrm{I}$. With $\mathrm{N}$ turns in the usable window area, the two inductances become

$$
L=\frac{{ }_{0} \mathrm{~N}^{2} \mathrm{~A}_{\mathrm{c}}}{\ell_{\mathrm{g}}}
$$

in which the usual assumption [15] is that the reluctance in the air is much larger than that in the core $\left(\ell_{0} / \mu_{0} \gg \ell_{m} / \mu\right)$, where $\mu_{0}$ is the permeability of ree space in the MKSA system.

From the flux distribution in Fig. 1la it becomes obvious that the coupled-inductor can now be built by use of only the U-core parts without the need for I core parts, as shown in Fig. 11b. Since the dc fluxes of the two windings now add, the effective air gap is doubled to $2 \ell$, to prevent saturation of the core. The self-indugtance of the primary and secondary of the coupled-inductor then becomes

$$
\mathrm{L}_{1}=\frac{{ }_{0} \mathrm{~N}^{2} \mathrm{~A}_{\mathrm{c}}}{2 \ell_{\mathrm{g}}}=\frac{\mathrm{L}}{2}
$$

Hence, as before equal current ripples are obtained for the two converters. Also, the same two windings are used in each case, resulting in equal copper losses. However, the core losses of the coupled-inductor configuration are significantly reduced since the I legs are completely eliminated. Depending on the actual geometrical shape of the original configuration, this may even approach saving close to half of the core material, and hence correspondingly reduce the core losses and size.

In this particular case, it becomes even more transparent how by integrating the two separate inductors into a single magnetic circuit, some of the common flux paths can be shared, saving in the process the core material. For example, the U-core of the second inductor served the purpose of closing the magnetic path of the $U$-core of the first inductor, and vice versa, with the net result the elimination of the I core legs.

Thus far we have demonstrated how by use of the coupled-inductor technique the savings can be made in two extreme cases: either all the savings are in copper losses, or all the savings are in core losses, with size and weight reduction in each case. This choice was purposely made to clearly present the two limiting cases. Of course, in practice, the coupled-inductor may be designed to fall anywhere between these two extremes thus saving both in copper and core losses as well as size and weight.

Finally, one should bear in mind that this is the least beneficial comparison, since clearly the savings will be significantly better when the coupled inductor is designed for unbalanced ripple current reduction (zero ripple current in particular) when its performance will be hard to match with separate inductors.

However, the practical feasibility of zero current ripple on only one side leaves one with a feeling of incompleteness, and a desire to accomplish this ideal goal simultaneously at both input and output sides.

\section{ZERO-RIPPLE SWITCHING DC-TO-DC CONVERTERS}

With the just-posed problem of zero current ripple at both input and output, there are several possible approaches to follow. For example, two coupled-inductor Ćuk converters can be cascaded as shown in Fig. 12. The first, input, converter could be designed for zero-input current ripple, while the second converter is adjusted for zero output current ripple. However, it is quite obvious that this would be a brute force solution, since not only that the input power would be processed twice through this cascaded connection, but the part count would be doubled and the original advantages of simplicity and reliability would therefore be diminished. Although one may attempt to further simplify this configuration by eliminating some component or rearranging the coupling, still it seems that a rather different and fundamental look is needed. Hence the following objective is posed:

Synthesize a switching $d c-t o-d c$ conversion structure which has the least number of components (switches, capacitors, inductors and/or transformers) and yet leads to the ideal dc voltage and current waveforms at both input and output simultaneously.
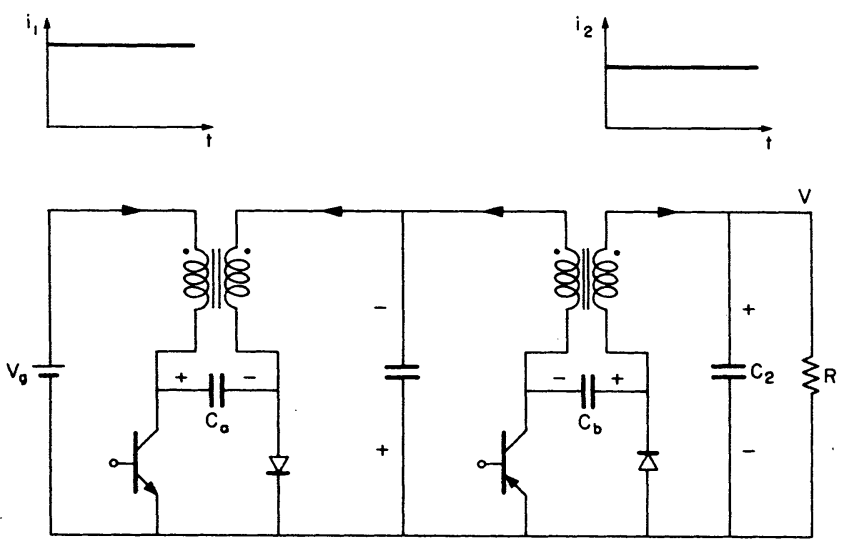

Fig. 12 Cascaded connection of two coupled-inductor Cuk converters 

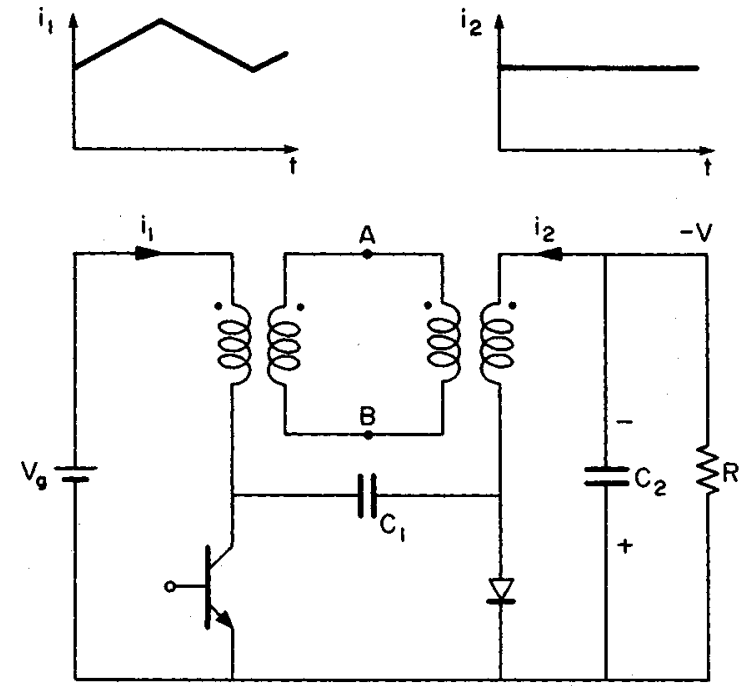

Fig. 13 Two cascaded coupled-inductor transformers in the coupled-inductor converter configuration still lead to a zero ripple at only one end.

This problem at first may seem formidable and impossible to achieve, but with the material outlined so far, the generalization of the coupledinductor concept seems to be a natural approach.

The first idea which immediately comes to mind in order to achieve this goal is to use two cascaded transformers in the coupled-inductor Cuk converter, as shown in Fig. 13. It seems that by adjustment of the first coupled-inductor for the matching condition $n_{1}=1 / k_{1}$, the input current ripple could be made to vanish, while with another matching condition $n_{2}=k_{2}$, the output current ripple could be reduced to zero at the same time. Hence, this is a potential candidate for the ultimate zero-ripple converter. The only problem, however, is that is does not work as described. Namely, zero-current ripple could be still obtained only on one side. There are insufficient degrees of freedom for the independent adjustment of zero ripple on the two separate coupled-inductors, since their cascade connection can be equivalently represented by a $\mathrm{T}$ model of the transformer.

It turns out that there is another more fundamental reason for it. One may recall that the reduction to zero current ripple at either end in the basic coupled-inductor converter is because both primary and secondary of the coupled-inductor are excited by some proportional stiff switching voltage waveforms. Namely, the switching source for the secondary is generated by the original energy transfer path through the capacitance $C_{1}$. Thus, in order to have two independent matching conditions for the two coupled-inductors in Fig. 13 , one would have to apply the same switching voltage source to the connection points $A$ and $B$ between the two coupled inductors, such as shown in Fig. 14, and resulting in both current ripples reduced to zero. Otherwise, without that excitation source for the secondary of the first coupled-
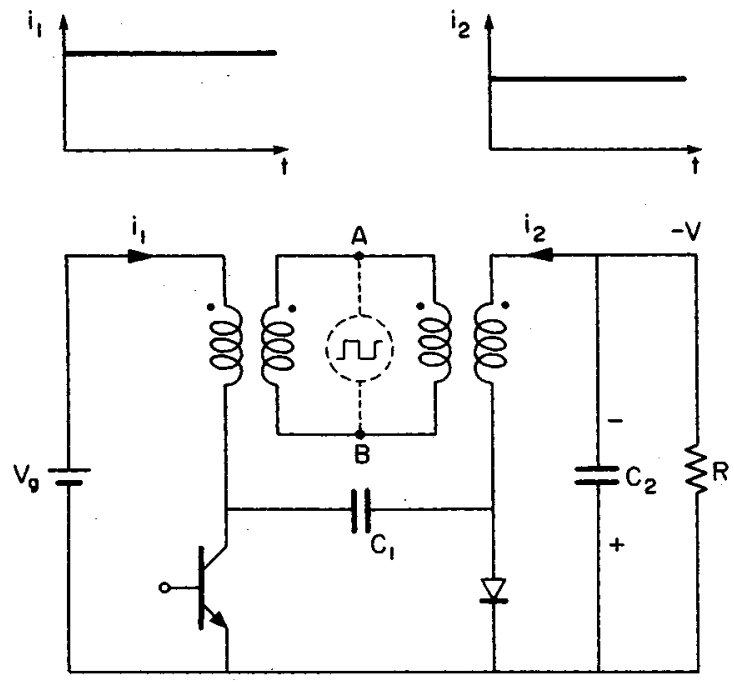

Fig. 14 To achieve zero current-ripple at both ends, a stiff switching voltage source is needed between the two coupled-inductors.

inductor transformer, and primary of the second cascaded coupled-inductor, the cascaded connection behaves just like a single transformer, with possible zeró current ripple on only one side.

Even though this attempt to cascade coupledinductor transformers is not successful yet, owing to the need for some means of imposing a stiff switching voltage across points A \& B in Fig. 14, the approach has not failed since it has pinpointed the crux of the problem.

The remaining puzzling question is:

How can we generate the required switching voltage source and insert it appropriately in the converter?

The attempt to generate this voltage source externally would again be a brute-force solution. However, some switching voltages already existing in the converter itself could perhaps be used. Unfortunately, the converter of Fig. 14 has only two such places: the primary of the first coupledinductor and secondary of the second coupledinductor. Application of either one to points A $\& B$ would short out one or the other coupledinductor, thus effectively reducing it to a single transformer configuration again.

The key step then becomes to find a switching topology which is abundant with such proportional inductor switching voltage waveforms and will hence allow multiple application of the coupled-inductor concept. However, we have already seen such a topology in Fig. 3b where it was just an intermediate and key step toward dc isolation introduction. To emphasize the availability of the proportional switching voltage waveforms, this configuration is shown again in Fig. 15 with the corresponding inductor voltage waveforms. 


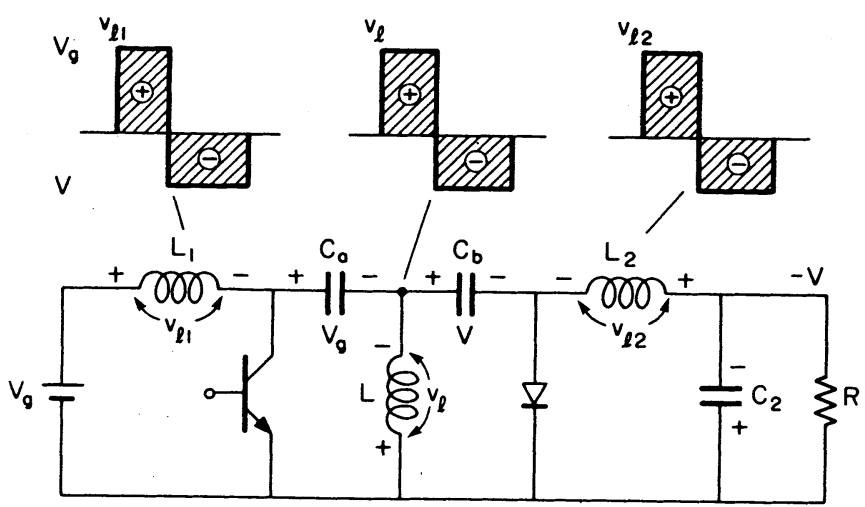

Fig. 15 The multiple of inductor switching voltage waveforms in this switching converter permits a multiple use of the coupled inductor concept.

Note that the voltage across the additional inner inductance $\mathrm{L}$ is again exactly the same as that across the other two inductors $\mathrm{L}_{1}$ and $\mathrm{L}_{2}$. Namely, it switches between the input ${ }^{1} \mathrm{c}$ voltage $\mathrm{V}$ and the output dc voltage $\mathrm{V}$, since the average $\left(g_{c}\right)$ capacitance voltages on $C$ and $C_{b}$ are $V$ and $\mathrm{V}$ respectively. Therefore, the configuration in Fig. 15 is in a form suitable for multiple application of the coupled-inductor concept.
It now becomes apparent that in the converter of Fig. 15, the inner inductance $L$ may be coupled either with the input inductor $\mathrm{L}$ for zero input current ripple, or it may be coupled with the output inductor $\mathrm{L}_{2}$ for zero output current ripple.

However, with a minor modification of the converter in Fig. 15, both current ripples may be reduced to zero simultaneously. In fact, the next step is quite obvious. The original inner loop inductance $\mathrm{L}$ can be replaced by two separate inductances $L_{a}$ and $L_{b}$ connected in parallel as shown in Fig. 16. Then by coupling the inductance $L$ to the input inductance $\mathrm{L}_{1}$, while separately coupling the inductance $\mathrm{L}_{\mathrm{b}}$ to the output inductance $\mathrm{L}_{2}$, both input and output current ripples may be made to vanish (actually pushed inside the converter into the $\mathrm{L}_{\text {and }} \mathrm{L}_{\mathrm{b}}$ windings). The two inductances $\mathrm{L}$ and $\mathrm{L}_{b}^{\mathrm{a}}$ are not coupled magnetically, but are only connected electrically in parallel. Hence this configuration has two magnetic lumps (two coupledinductors $M$ and $M$ ) as shown in Fig. 16b. In fact the two coupled-inductor configurations $M_{a}$ and $M$ are connected in cascade and the required switching voltage source $v_{\text {is }}$ isplied to their interconnection points $\mathrm{A} \& \mathrm{~L}$, just as postulated in Fig. 14. Thus the only step required in the configuration of Fig. 14 is to split the coupling capacitor into two series capacitors and to use their common point as the source of the additional switching voltage wayeform.

a)
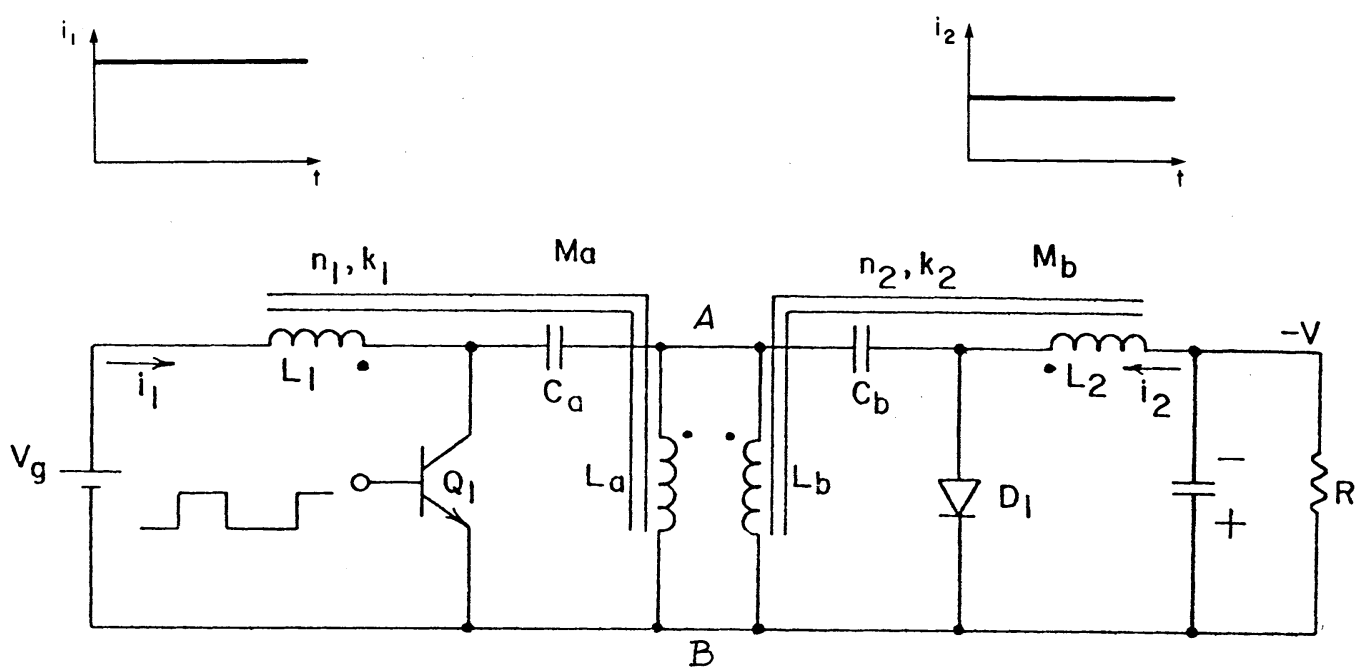

b)

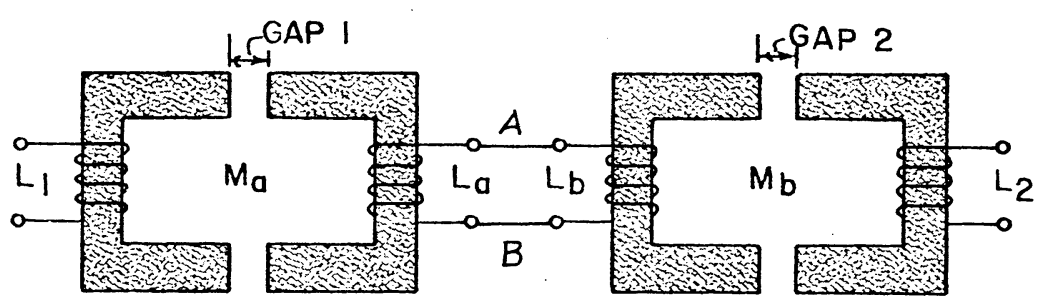

Fig. 16 zero -ripple Cuk converter (a) implemented by use of the two cascaded coupled-inductors (b). 
a)

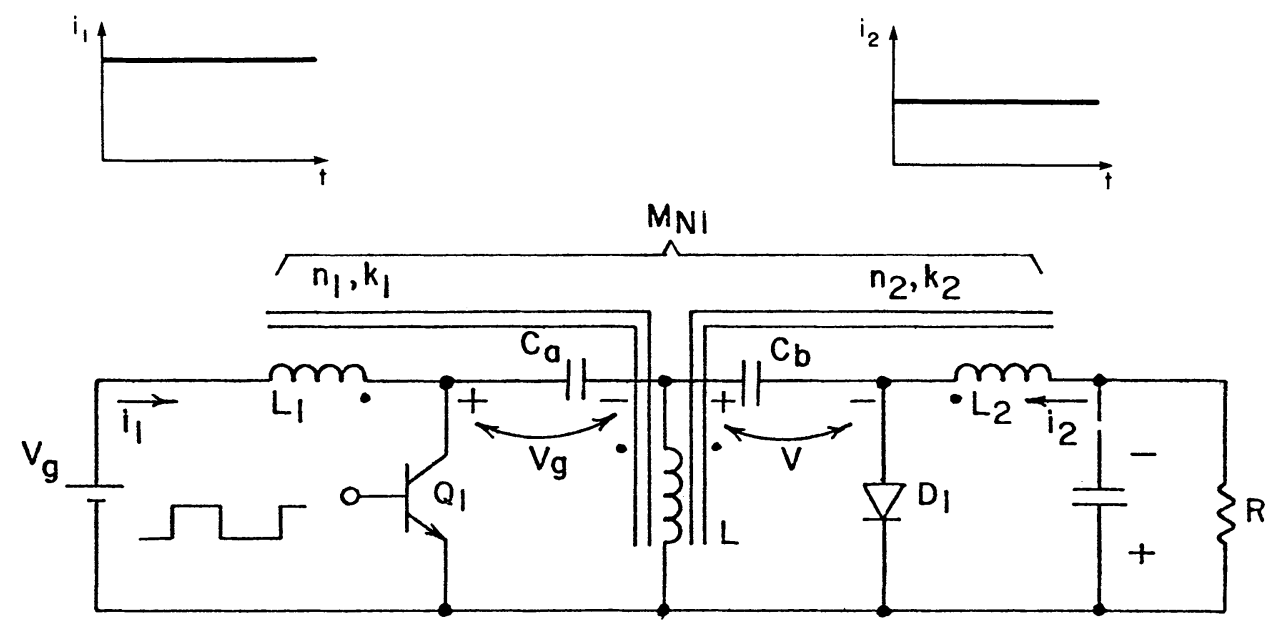

6)

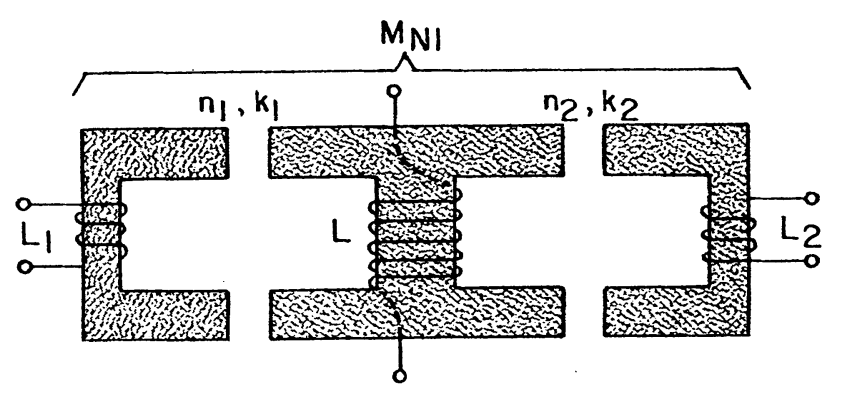

Fig. 17 Zero-ripple Cuk converter (a) implemented by a single magnetic circuit with three windings (b).

a)
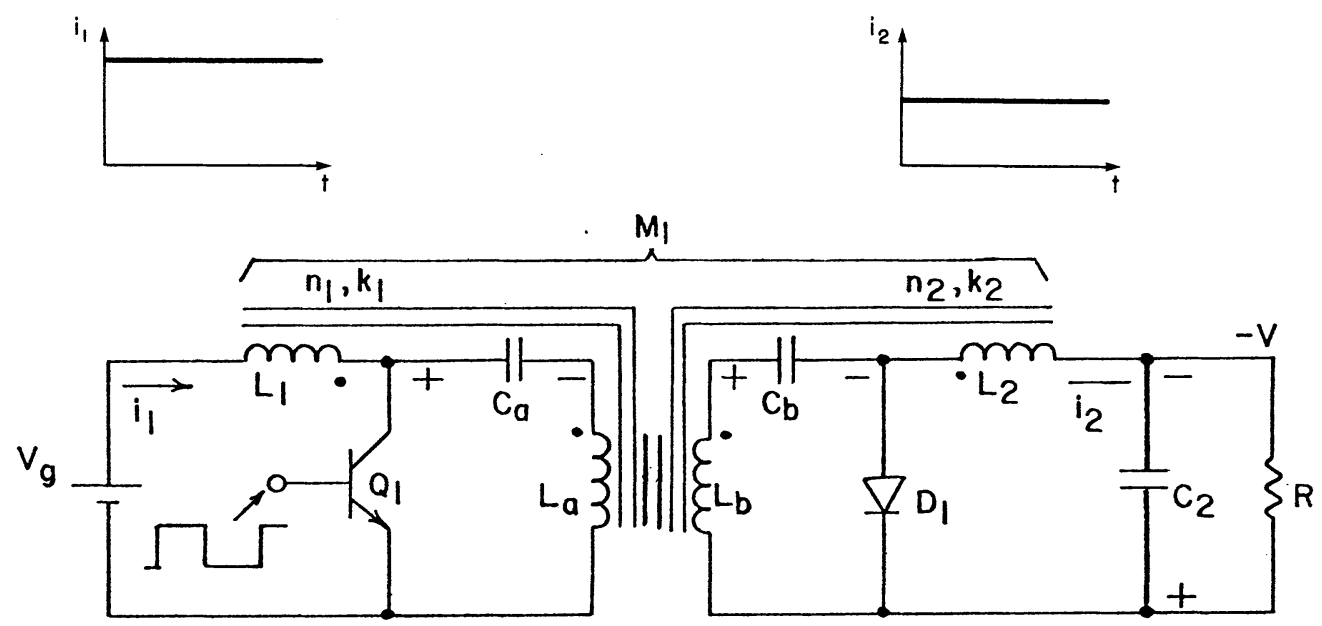

6)

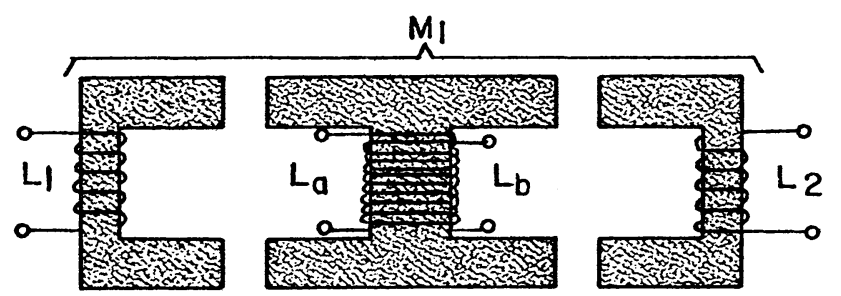

Fig. 18 zero-ripple dc isolated Ćuk converter $(a)$ and its magnetic circuit realization (b) 
As seen in Fig. 16b, by varying the coupling coefficient $k_{1}$ in the first $M$ coupled-inductor through the air-gap change, the matching condition is obtained when $n_{1}=1 / k_{1}$ where $n_{1} \triangleq \sqrt{L_{1} / L}$, and consequently dc input current is obtained. "Likewise, by the corresponding matching condition $\left(\mathrm{n}_{2}=\mathrm{k}_{2}\right.$; $\left.\mathrm{n}_{2} \triangleq \sqrt{\mathrm{L}_{\mathrm{b}} / \mathrm{L}_{2}}\right)$ in the other coupled-inductor $\mathrm{M}_{\mathrm{b}}$, the output current ripple can be adjusted to zero as weil. Note that the two coupled-inductor adjustments are independent of each other.

It now seems that we have obtained finally the ultimate solution postulated in Fig. 14 and posed at the beginning. However, although zero-current ripple is obtained at both ends, it is achieved by some sacrifice in the complexity. Namely, we now have again two magnetic lumps as in the original basic Cuk converter (Fig. 2) and even four windings instead of the original two. Thus, in line with the original approach adopted at the beginning of the development of new, better converter topologies [1], one would like to further simplify the topology of Fig. 16 and yet retain its desirable zero-ripple properties.

The sequence of the development outlined so far clearly indicates that the electrical content is maximally simplified and best utilized in the converter of Fig. 15. The magnetic content of the converter in Fig. 16 however, still has some room for improvement and simplification. For example, the two magnetic lumps in Fig. 16b could be further reduced and integrated into a single magnetic circuit by magnetically coupling the windings $\mathrm{L}$ and $\mathrm{L}_{b}$ through merging of their cores to result in the magnetic core structure of Fig. 17b. But now, two windings $\mathrm{L}_{\mathrm{a}}$ and $\mathrm{L}_{\mathrm{b}}$ being electrically connected in parallel, can be reduced to a single winding $\mathrm{L}$ and the simplified switching converter configuration of Fig. 17a is obtained. Note, however, how even the single winding $\mathrm{L}$ in the core structure of $\mathrm{Fig}$. $17 \mathrm{~b}$ effectively plays the role of the previous inductances $\mathrm{L}_{\mathrm{a}}$ and $\mathrm{L}_{\mathrm{b}}$. Namely, the flux that this winding $\mathrm{L}$ produces couples to the input winding $\mathrm{L}_{1}$ through left-hand part of the central core producing the effect of $\mathrm{L}_{1}, \mathrm{~L}_{\text {a }}$ coupling in the previous configuration, while it also simultaneously couples to the output winding $\mathrm{L}_{2}$ through its complementary flux in the right-hand part of the central leg, emulating the previous $L_{b}, L_{2}$ coupling. Notice also that in this magnetic configuration (Fig. 17b) as in the previous one (Fig. 16b), the input $\mathrm{L}_{1}$ and output $\mathrm{L}_{2}$ inductors are not directly coupled, thus preventing the potential interference of this extra coupling with the zero-ripple adjustments.

Indeed, the flux generated by the winding $L_{1}$ is almost completely closed through the inner leg (containing $\mathrm{L}$ winding) owing to its low reluctance when compared to the high reluctance of the parallel magnetic path containing air gap 2. Thus, the paralle1'bars in Fig. 17a show that the inner inductor $\mathrm{L}$ is coupled to the input inductor $\mathrm{L}$ and to the output inductor $\mathrm{L}_{2}$, which are virtually not coupled to each other. This convention for schematically illustrating separate inductance couplings is used throughout the remaining figures.
As before, by adjustment of the two air gaps, zero current ripple can be obtained simultaneously. However, unlike the situation for the core configuration of Fig. 16b, in the core configuration of Fig. 17b the two air gap adjustments are interdependent: adjustment of only one air gap affects the current ripple on both sides. Nevertheless, the adjustments are highly convergent and lead in a few iterative steps to a zero-ripple case, as demonstrated later in Section 5 in the experimental verification. The other alternative is the use of fixed air gaps (designed for given dc flux capabilities) of input and output inductors) and use of turns ratio adjustments of the outer legs with respect to the inner leg. This method of course does not have the interdependence problem, as also illustrated in Section 5.

The converter in Fig. 17 is a good example of the generalization of the coupled-inductor concept whereby three previous $1 y$ separate inductors are merged into a single magnetic circuit. In addition, the performance approaches that of an ideal dc-to-dc transformer since current ripple is reduced to zero at both input and output sides (actually pushed into the inner winding L). From the conceptual viewpoint the converter now consists of only two major parts: an electrical part in which electric charges flow, and a magnetic part in which the flux flows, which are appropriately connected to result in the useful function: ideal dc-to-dc conversion.

While approaching the properties of an ideal dc-to-dc transformer, the converter of Fig. 17 and all other coupled-inductor extensions are lacking the practically very important dc isolation property. Our approach again should be the same as that for all the previous developments: how to build-in this property with the minimum of extra elements. The isolation property is easily recovered by a step which is completely analogous to that shown leading from Fig. 3b to Fig. 3c. Namely, by addition of a single winding to the inner leg of the magnetic circuit of Fig. 17b, and then electrically separating the two windings on the inner leg, the isolation is obtained as shown in Fig. 18a, with no additional magnetic material required. of course, zero-current ripple properties on both ends remain.

The added isolation transformer now has a double role: it not only provides the isolation. but also through coupling with input and output inductances provides a means for achieving dc currents at both ends simultaneously, and at the same time leads to better magnetic core utilization.

From the magnetic circuit realization in Fig. $18 \mathrm{~b}$, it may seem that a rather special magnetic core configuration is needed which even does not look like a single-core structure. In fact, the core configuration used consists of two sets of U-cores, as compared to the needed three sets of $\mathrm{U}$-cores if the two inductors and isolation transformer were implemented with separate magnetic circuits. However, this was done only for conceptual reasons to clearly explain each step of the development and accompanying savings. There 
is a large number of core shapes and configurations with two air-gaps which could be implemented. For example, a standard EI magnetic core can be used for the practical implementation of the magnetic circuit in Fig. 18b, such as shown in Fig. 19 . It differs from the standard usage only in that its outer legs contain air-gaps, as opposed to the usual implementation in which the inner (central) leg is gapped and not the outer ones. The fact that it consists also of three bobbins mounted on each leg of the EI core structure is not unusual and is regularly used in three-phase transformer applications.

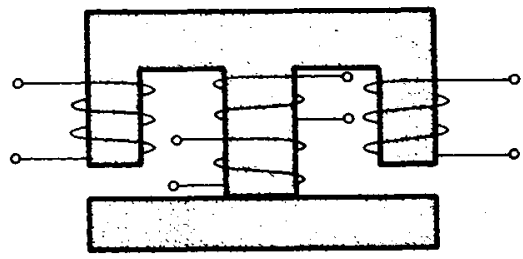

Fig. 19 An alternative EI core realization of the single magnetic circuit for the zero-ripple converter of Fig. 18a: inner leg windings provide de isolation, the outer leg windings input and output inductance.
A truly aptimum de converter is obtained which has both outstanding features: true de currents and dc isolation in the simplest possible topology consisting of a single magnetic circuit with four windings, transistor, diode, and two capacitors.

This is illustrated in Fig. 20, in which the converter hardware realization (Fig. 20a) is equivalently represented by the ideal dc-to-dc transformer (Fig. 20b), hence the initial problem posed in Fig. I has been solved.

From the conceptual viewpoint, this is the first time that such diversified magnetic components, such as inductors and transformers exclusively used until now as separate components in switching structures, are integrated into a single magnetic circuit with multiple windings.

A natural extension of this zero-ripple converter configuration (Fig. 18) to multiple outputs is shown in Fig. 21. There, a single magnetic circuit $M$ with six windings appropriately coupled is capable of providing zero current ripple not only at the input but simultaneously at both outputs as well. The actual physical implementation of its magnetic circuit shown in Fig. $21 \mathrm{~b}$ is a simple three dimensional extension of the previous EI core configuration. It required addition of only one U-core, which shares a common leg with the central leg of the E-core as seen in Fig. $21 \mathrm{~b}$.

a)

6)
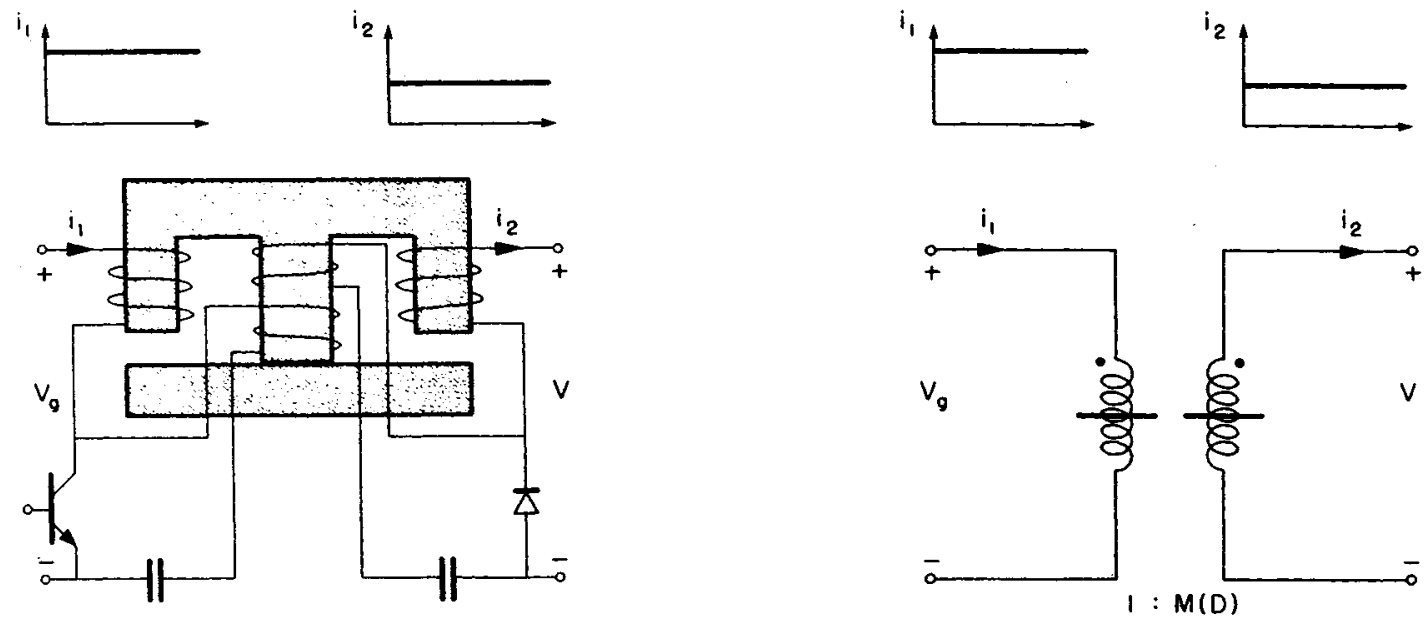

Fig. 20 The simplest realization (a) of the ideal dc-to-dc transformer (b) consists of the four winding magnetic circuit, transistor, diode and two capacitors. 
Then, the three windings are placed on this common central leg, while the input and two output windings are placed on the three outer legs. Again, as before the outer legs are gapped while the central leg is not. It is interesting to point out that a magnetic core configuration of the same construction has been recently proposed and used [22], although for a different application in which the additional U-core magnetic leg serves for control winding purposes. The extension of this zero-ripple configuration to other multiple outputs (three or more) is then quite obvious.

There are a number of extensions and variations that can be used in multiple-output configurations, if zero-ripple is not required at both input and all outputs. For example in the twooutput dc isolated converter of Fig. 22, two output inductors can be coupled to the input inductor, but not to each other, by use of the core configuration of Fig.19 with the input inductor on the inner center leg. Then, zerocurrent ripple can be obtained simultaneously at both outputs, which is usually of overriding practical importance. Also, the core utilization will be best since all three windings will optimally use air gapped core structure for their maximum required dc current capability. Furthermore, the remaining magnetic lump for the isolation transformer is easy to design, since it is independent and not constrained by additional coupling.

a)
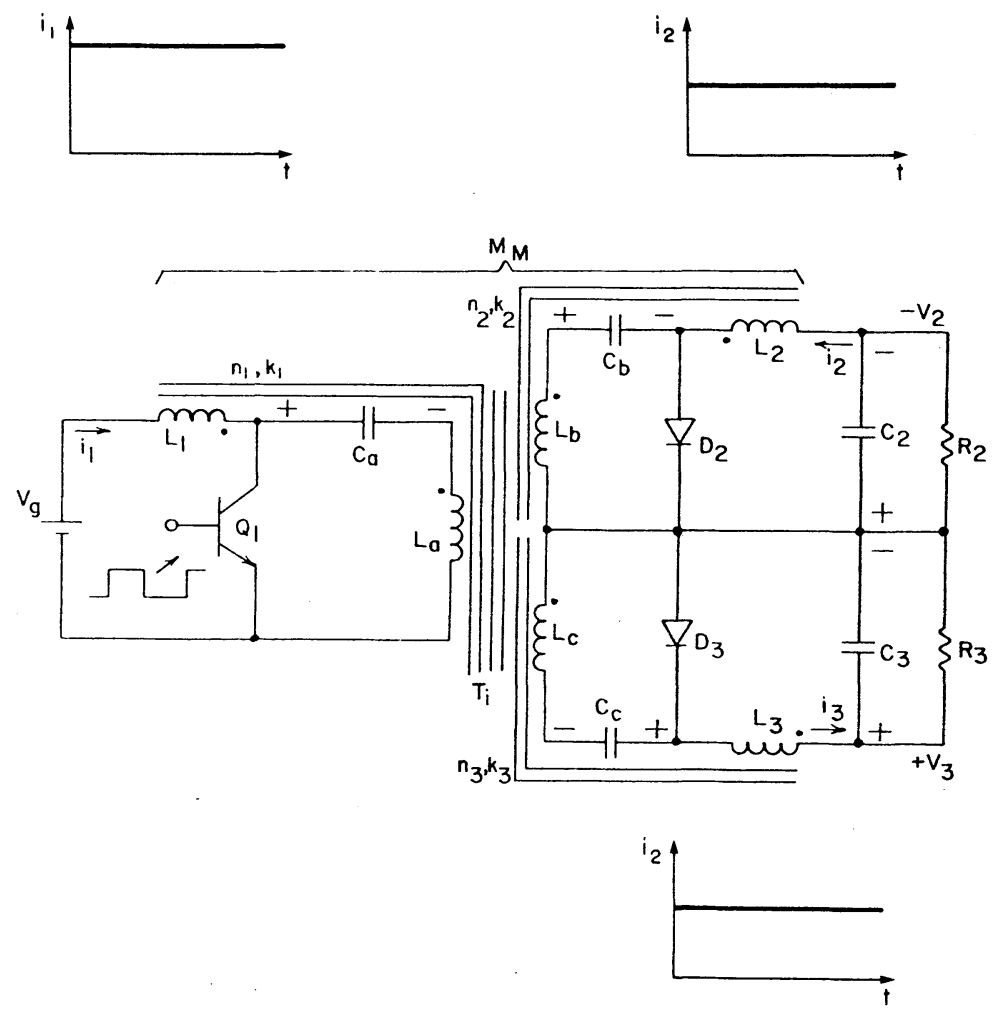

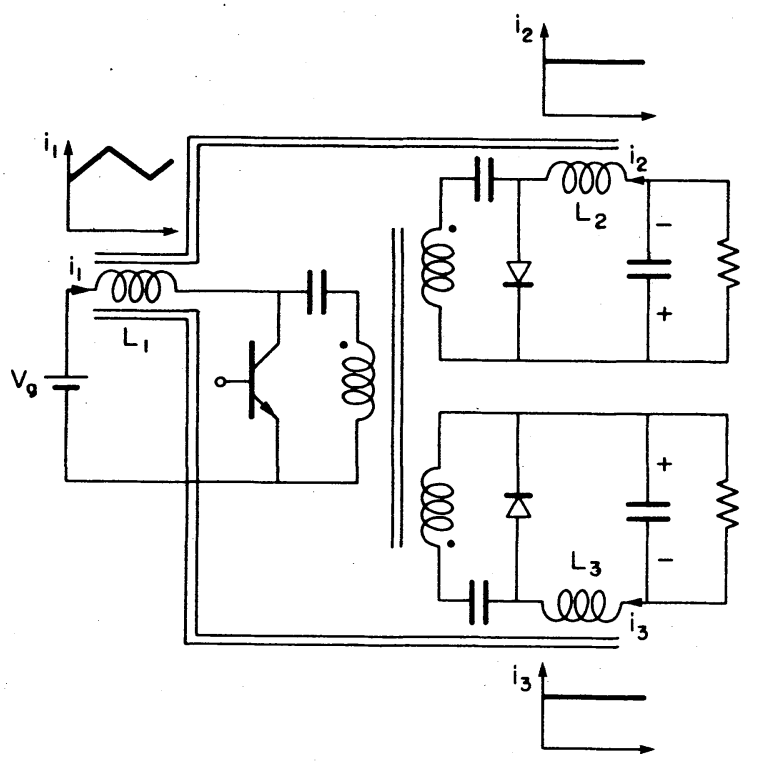

Fig. 22 switching $d c-t o-d c$ converters with zeroripple currents at both outputs implemented by EI core of Fig. 19.

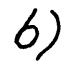

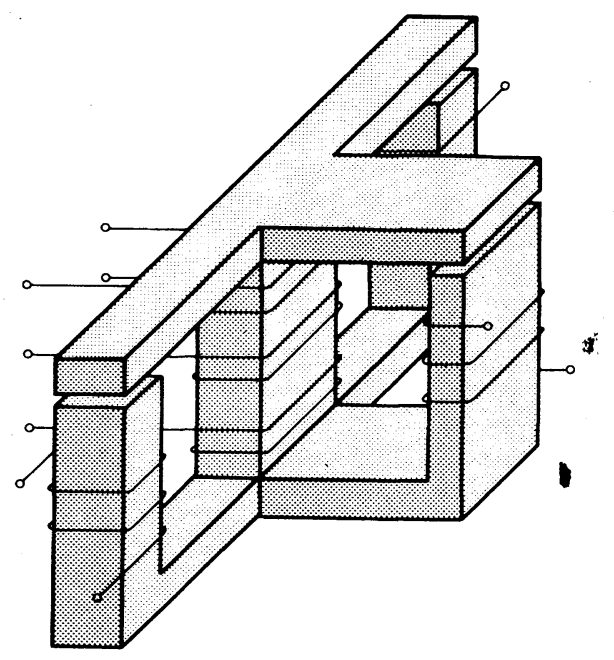

Fig. 21 Two-output zero ripple dc isolated Cuk converter $(a)$ and its single magnetic circuit
realization (b). 
A number of interesting extensions and variations of the multiple-output converter with coupledinductors (two or three magnetic lumps) together with detailed analysis and practical considerations can be found in $[12,13,14]$.

Here only a limited number of switching configurations with zero-ripple current on both sides could have been presented, so only a few which appear to be basic for the understanding of the concept are shown. A number of other very interesting zero-ripple extensions have been proposed and can be found in [11].

\section{EXPERIMENTAL VERIFICATION OF ZERO-RIPPLE}

The main purpose of the experiments was to verify the feasibility of the simultaneous reduction of current ripple to zero by use of the several switching converter topologies proposed and their accompanying magnetic circuits. The objective was not to go into detailed analysis of several complex magnetic structures suggested, nor to experimentally verify their accompanying design equations, since that will be the subject of some detailed future papers. Thus, the experiments were designed to prove the concept and not to indicate or suggest any preferred practical implementation.

There are two main approaches [21] by which one can design the coupled-inductor experiment to demonstrate the current ripple reduction with changes of the relative ratio of the coupling coefficient $k$ and effective turns ratio $n$, and to prove that there is, indeed, the practical feasibility of the zero ripple condition on both ends: a) by varying the air gap and hence coupling coefficient $k$, while keeping the effective turns ratio $n$ constant, a continuous approach to and through zero-current ripple is possible.

b) by varying the turns ratio while keeping the air-gap fixed, an approach to and through zero- current ripple is made possible but now in discrete steps, whose size depends on the incremental turns ratio change.

For verification of zero current ripple along both of the two routes, the topological configuration of Fig. 18a was built such that the interconnection points for all magnetic components were left open so the various magnetic structures proposed in the previous Section could be easily at tached.

\section{(a) Variation of the air-gaps}

This first laboratory experiment is actually a generalization of the experiment originally performed in [21] to prove the actual feasibility of zero current ripple in the basic coupledinductor Ćuk converter by actually going through the zero current ripple continuously.

The magnetic circuit structure of Fig. 18b is made by use of two sets of U-cores and four windings wound appropriately. The two air gaps are then made variable by use of the two micropositioners as shown in the set-up of Fig. 23b. The windings are then connected to the converter according to the dot designation of Fig. 18a, and the following is observed:

The variation of the air gap 1 only (left-hand air gap), results in the continuous change of the current ripple from its usual positive slope (triangular waveform), through zero (straight line! to the negative slope (inverted triangular waveforms) first time observed in the coupled-inductor structures as seen in Fig. 23a. As expected this variation of the air-gap affected the other output current ripple as well, since the flux distribution of the inner windings is also affected by this variation. The air gap 1 is then adjusted for zero-input current ripple.

a)
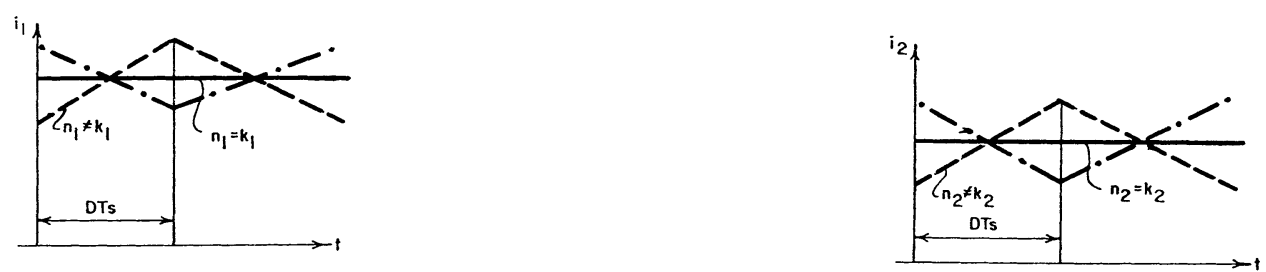

6)

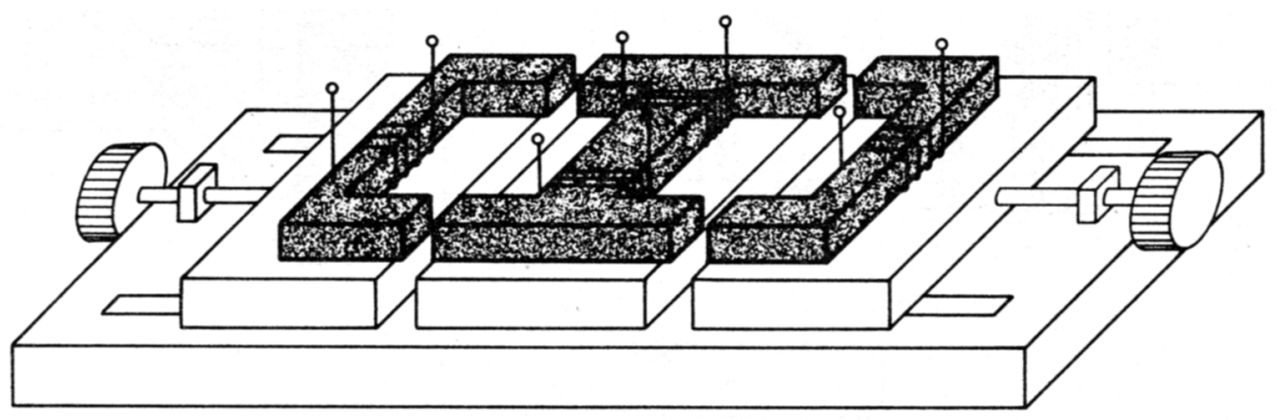

Fig. 23 Variation of air gaps in the magnetic circuit (a) for the converter of Fig. 18 result in the continuous. change of the two ripple currents from positive, through zero to negative slope $(b)$. 
The subsequent variation of the air gap 2 only, leads also to the continuous change of the output current ripple from positive through zero, to "negative" current ripple. Air gap 2 is then adjusted for zero-ripple output current. At that position the previously adjusted input current is slightly offset from zero-ripple condition. However, another iteration of the air gaps 1 and 2 adjustments leads to a perfect zero-ripple condition simultaneously on both sides.

One feature of the magnetic structure of Fig. 23 may appear at first to be troublesome. The isolation transformer has built in air-gaps in its magnetic path and potentially increase its leakage inductance. However, it was convincingly demonstrated in [10] on the coupled-inductor experimental setup analogous to that of Fig. 23, that to the first order the leakage inductances remain constant independent of the gap length. Thus, isolation transformer performance is not adversely affected in this single magnetic circuit configuration.

This laboratory experiment convincingly demonstrates the feasibility of a zero current-ripple converter, provided the single magnetic circuit structure is designed appropriately. While it very nicely demonstrates this new generalized coupledinductor concept, the variable gap magnetic structure very likely is not going to be the preferred realization, even though possibilities may exist, such as ferrite pot cores with screw adjustable air gaps usually used for inductor turning purposes. The configuration with fixed air gap structure, such as the one of Fig. 19 from practical considerations is easier to implement, as shown next.

\section{(b) Variation of the turns ratio}

Since the EI core configuration of Fig. 19 was not readily available (it comes either ungapped or with central leg gapped) an ungapped ferrite EE core was chosen and the outer legs of one E-core were ground to provide two air gaps (courtesy of Jet Propulsion Magnetic Laboratory and Colonel McLyman). Note, however, that, if needed in production quantities, the EI gapped core configuration of Fig. 19 could be just as readily obtained as the customary central gap structure, especially with ferrite cores. Another practical feature of the core configuration in Fig. 19 is that all the windings can be wound on bobbins and slipped on core legs, which was also used for this experiment. The two windings for the isolation transformer are wound bifiliar on the central leg bobbin. Then, the number of windings on the outer legs were increased above that of inner windings until zerocurrent ripple is achieved on both sides. From the practical viewpoint, even with the relatively imprecise adjustments, current ripple can be easily reduced for two orders of magnitude (actually shifted from the input and output side to the inner isolation transformer windings).

While the experiments qualitatively confirmed the expectation, one interesting difference with the coupled-inductor zero-ripple result of Fig. 5 was noted. There, all the current ripple is shifted to the primary side, which retained the same triangular waveform (the same input current ripple as before the coupling). In other words, primary and secondary current flow in their respective input and output circuits, and are only related through the transformer (or better coupledinductor) equivalent circuit model. In the converter of Figs. 18 and 20, they are in addition forced to be identical during the portion of the switching cycle. For example, during the interval when the transistor is off, the input inductor current is the same as the primary current of the isolation transformer. Hence, in the zero-input current ripple case, the primary current of the j.solation transformer has a flat part during this interval. However, during the complimentary interval when the transistor is turned on, primary current does retain its familiar positive slope which indicates that the ripple-current is being pushed inside the converter into the winding. Of course, if it were flat that would indicate infinite magnetizing inductance of the isolation transformer a physical impossibility.

A number of variations for the practical implementation of the coupled-inductor configurations is contained in [19] and can be easily updated for their implementation in zero-ripple configurations

\section{INTEGRATED MAGNETICS CONCEPT}

Apart from the usefulness and practical advantages of a number of zero ripple switching configurations outlined so far, their significance goes even beyond, since they help to bring about a new and general concept which can be applied with success to many switching structures.

The coupled inductor extension of the Cuk converter [21], was the crucial first step in that direction. There, from the conceptual viewpoint, the two magnetic components (inductors), which are normally and exclusively used separately to perform their function in switching circuits, were for the first time integrated into a single magnetic circuit (single core) with two windings. While it looked like a classical ac transformer from the constructional viewpoint, it indeed performed the function of two separate inductors, when polarity marks and actual current directions are taken into account. Furthermore, it even outperformed the separate inductors by significantly reducing the size, weight and losses as demonstrated in Section 3.

The natural outgrowth and in fact the generalization of this concept is achieved, when in Section 4 it is extended to include ac transformers as well. Thus, such diversified magnetic components as inductors and transformers, used exclusively until now as separate magnetic components, are now integrated into single magnetic circuit with multiple windings. Besides apparent simplification, the converter performance is significantly improved (ripple currents reduced to zero) with additional savings in size and weight and 
increased efficiency. For this process of merging the separate magnetic components into an integral magnetic circuit with accompanying savings in size and weight owing to the elimination of some magnetic flux paths a generic name integrated magnetics is proposed.

Even some analogy can now be drawn with the process which led to the transition from discrete to integrated semiconductor circuits. Integrated semiconductor technology appeared in the late fifties when the need arose for the new technology which could accomodate the increasing complexity of semiconductor circuits by eliminating the interconnection of discrete parts. For example, in the integrated version of an NMOS inverter gate (shown in Fig. 24a implemented in NMOS poly-silicon selfaligned gate technology with the enhancement load) the external electrical connection between the upper and lower transistor required in discrete version is now eliminated, since it is automatically provided in the semiconductor media itself. In the case of the magnetic circuits, the transition from discrete magnetic components to integrated magnetic circuit, leads to the elimination of magnetic interconnection paths in analogy with previous electric interconnection paths. For example, in transistion from two separate inductors to a coupled inductor configuration (Fig. 11a and b) two I magnetic cores are eliminated. For another example of Fig. 24b, the transition from two separate inductors and a transformer into a single integrated magnetic circuit results in similar elimination of magnetic core material, this time two E-cores.

In the integrated semiconductors, the semiconductor is a common media into which different functions are engraved, such as transistors, diodes, resistors and even capacitors with the electric charge as a binding carrier. In the integrated magnetics, the magnetic core is a common media around which functions of inductors and transformers are built with the flux as a binding carrier. In both cases, however, proper voltage and current excitation of their terminal contacts is necessary for the desired component functions to be related.

One of the critisms which could be raised against the single magnetic circuit is its inflexibility that is, it is dedicated to the particular switching converter topology, and could have only a linited use in other configurations. In other words it is not a general purpose component such as discrete transistors and individual inductors and transformers are. In the integrated semiconductor circuits that flexibility is also lost with all components interconnected performing only an overall dedicated function. However, except at a laboratory level, one very rarely tears apart even discrete semiconductor circuits to recover the parts and built a new discrete circuit. In the switching power converters, even the separate magnetic components are so much tied to the particular design requirements, such as voltage, current and power rating or operating frequency and size requirement, that it is virtually impossible to reuse it in any other design. Therefore, in neither case the added inflexibility appears to be the limitation.

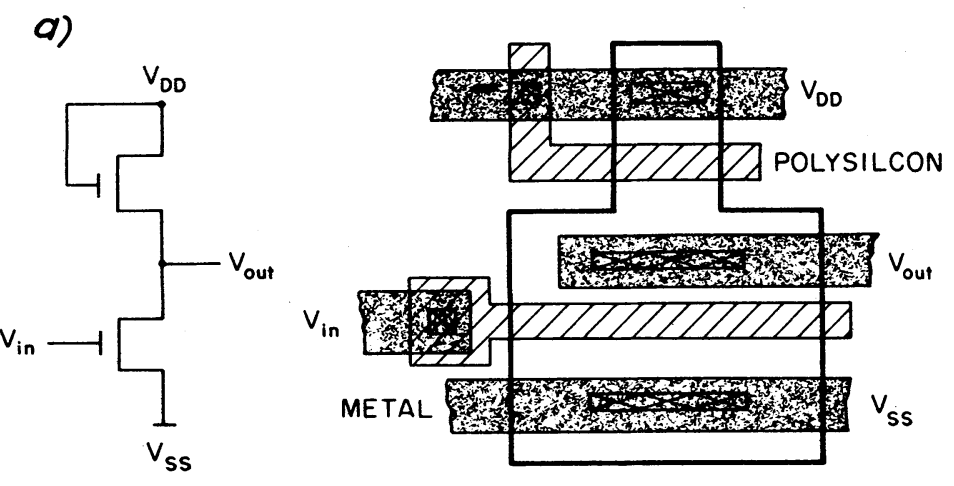

b)
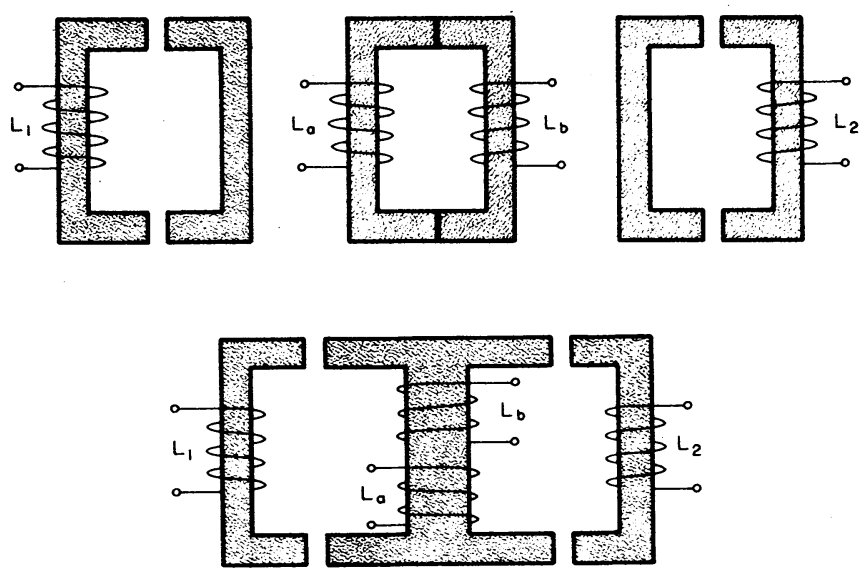

Fig. 24 Analogy between the integration of the semiconductor components $(a)$ and the integration of magnetic components (b).

\subsection{Applications of the Integrated Magnetics concept}

This new concept of integrated magnetics is applicable to a broad spectrum of electrical circuits involving magnetic components. It leads to the similar overall performance improvements in other switching converters, coupled with the simplified configuration, and reduced component count, size and weight. To substantiate this general claim, this concept is now illustrated on several other switching configurations with similar benefits. For example, it can be applied to the SEPIC converter [23] shown in Fig. 25a. When the input inductor $\mathrm{L}$ and the isolation transformer $\mathrm{T}_{4}$ are integrated into a single magnetic circuit $M_{p}$, a converter with zero input current ripple is obtained as shown in Fig. 25b. Still another example is a converter of Fig. 26a, which is a dual counterpart [ 7 ] to the previous converter. Merging the output inductor $\mathrm{L}_{2}$ and isolation transformer $\mathrm{T}_{5}$ into a single magnetic circuit $M$, a converter of Fig. 26b with zero output current ripple is obtained. 


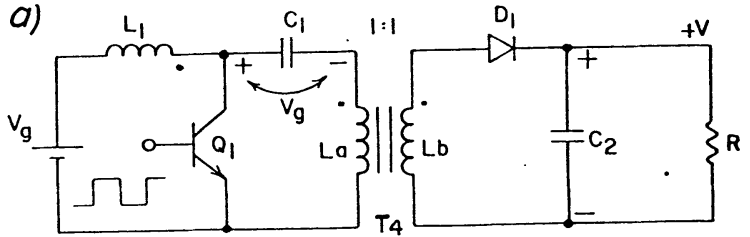

b)

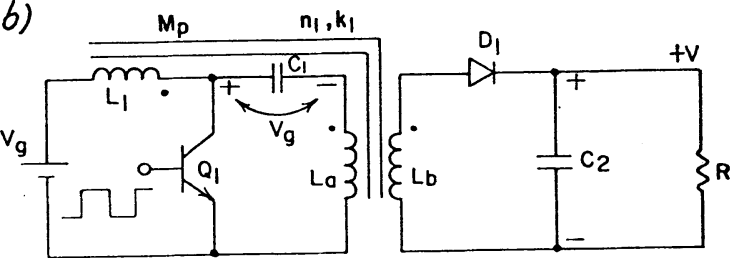

$1: 1$

Fig. 25 Integrated magnetics concept when implemented to SEPIC converter (a) results in zero-input current ripple converter in $(b)$.

However, the application of integrated magnetic concept is not limited to the switching dc-to-dc converters only. Other switching configurations performing qualitatively different functions, such as dc-to-ac inversion, or power amplification, may also utilize this concept to advantage. For example, this concept may be directly applied to a new pushpul1 switching power amplifier structure [6,17] shown in Fig. 27 implemented by use of two dc isolated Ćuk converters. Each converter's isolation transformer may be integrated with its corresponding input and output inductors to result in only two magnetic lumps and zero-current ripple on both sides.
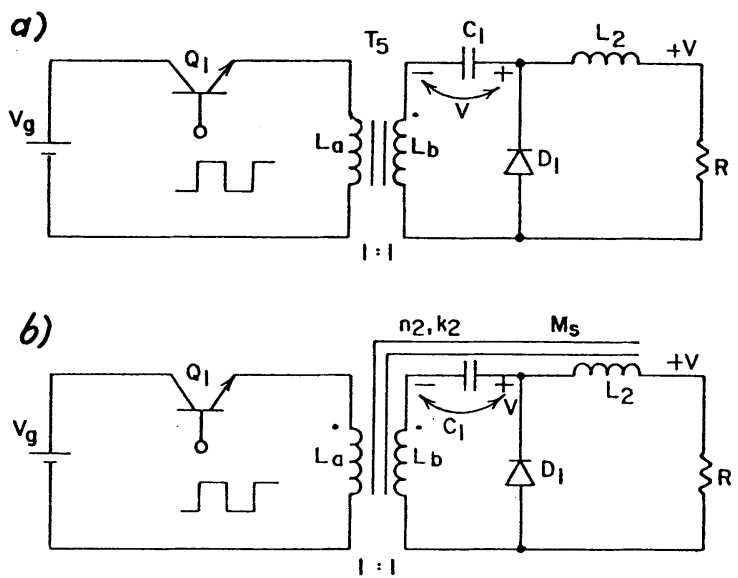

Fig. 26 Integrated magnetics concept when implemented to dual of SEPIC converter (a) results in zero output current ripple converter in (b).

components can be merged into an integral magnetic circuit with multiple windings. The prerequisite for such simplification of the arbitrary switching configuration shown in Fig. 28a is the existence of synchronized and proportional voltage waveforms on the inductors and transformers as shown in Fig. $28 \mathrm{~b}$. The voltage waveforms may even take a different shape other than rectangular, as long as their proportionality is retained [21]. Thus, Fig. 28 indicates the generality of the integrated magnetics concept.

व)
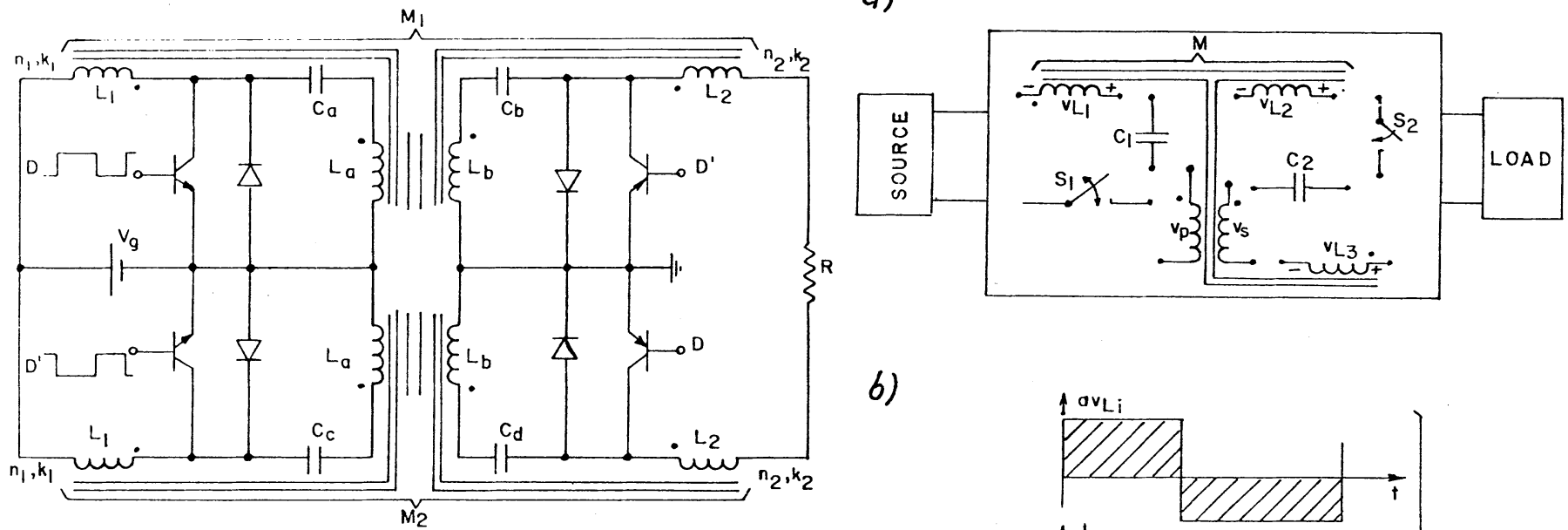

6)

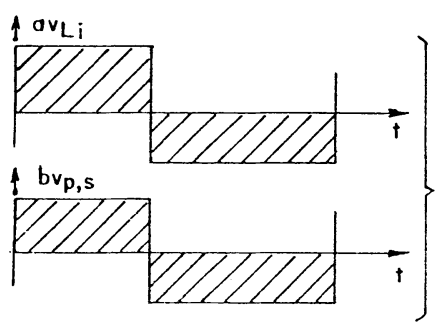

All these examples now illustrate how in a complex switching configuration consisting of a number of storage elements (inductors, transformers and capacitors) and switches interconnected in such a way to perform some useful function (such as dcto-dc conversion, dc-to-ac inversion, or power amplification), the otherwise separate magnetic
Fig. 28 Generalization of the integrated magnetic concept to any switching structure (a) and the prerequisite for its implementation (b). 


\section{EVOLUTION OF ZERO RIPPLE SWITCHING CONFIGURATIONS}

The search for more efficient, low noise, new switching converter topologies was originally motivated by the desire to reduce or possibly eiliminate some of the major problems which limit

"switchers," such as the large pulse currents at either the input or the output port or even at both. For example, in a conventional buck-boost (flyback) converter both input and output-port currents are large pulses leading to severe conducted and radiated electromagnetic interference (EMI). The basic Cuk converter (nonisolated version) was a substantial step in the direction of reducing this problem by creating nonpulsating input and output, currents. However the unique topology of the Cuk switching converter and in particular, proportional voltage waveforms on their two inductors, has led to a powerful new concept--the coupling of inductors. Besides the

a) NONISOLATED VERSIONS
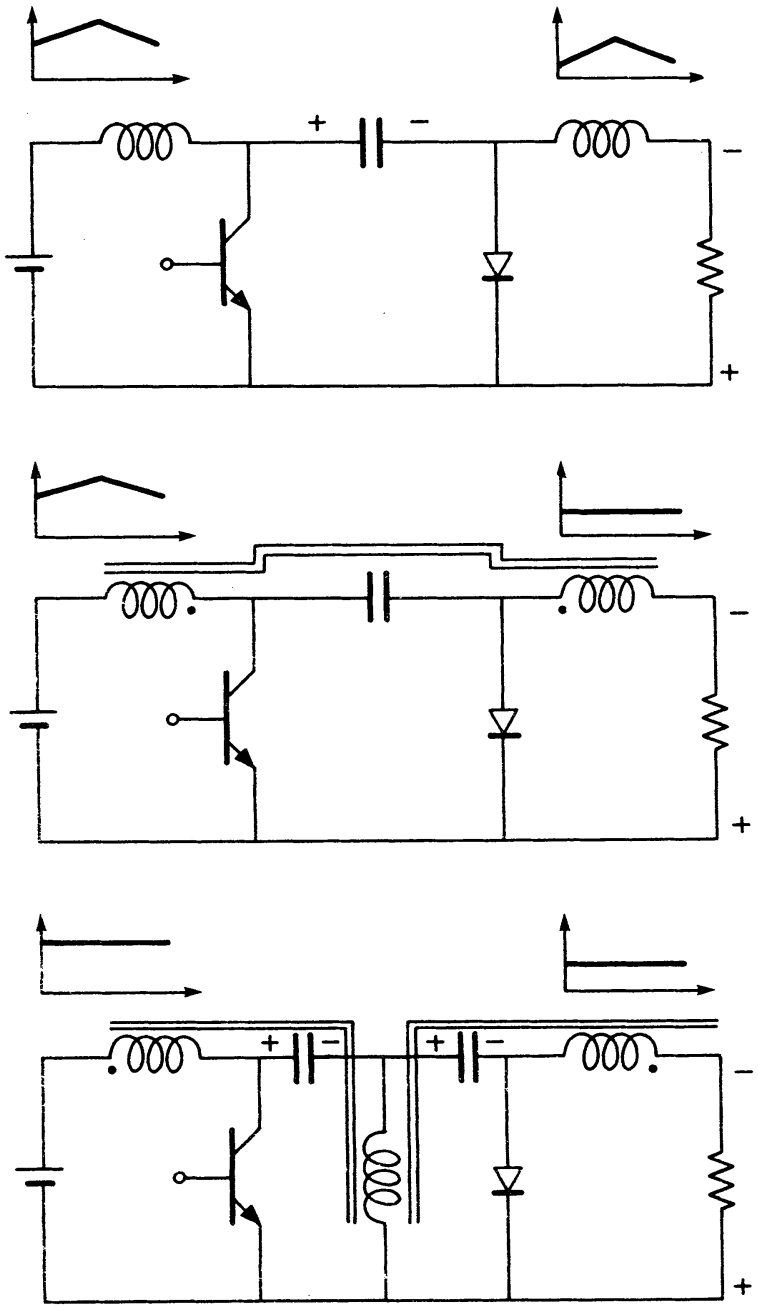

obvious reduction in complexity, yet another significant advancement has been accomplished: current ripple at either input or output is not only reduced but completely eliminated. The natural outgrowth of this new technique of coupling the inductors is a switching configuration which exhibits a single magnetic circuit with three windings and achieves zero current ripple at both ports simultaneously. The major cornerstones in the development of the nonisolated converter configurations are summarized in Fig. 29a.

For many practical applications dc isolation between source and load is often required. The next key step in the development is the incorporation of an isolation transformer in an optimum single ended manner, which leaves the fundamental features of the basic Cuk converter intact. Hence coupling of the input and output inductors leads again to zero current ripple at either end.

b) ISOLATED VERSIONS
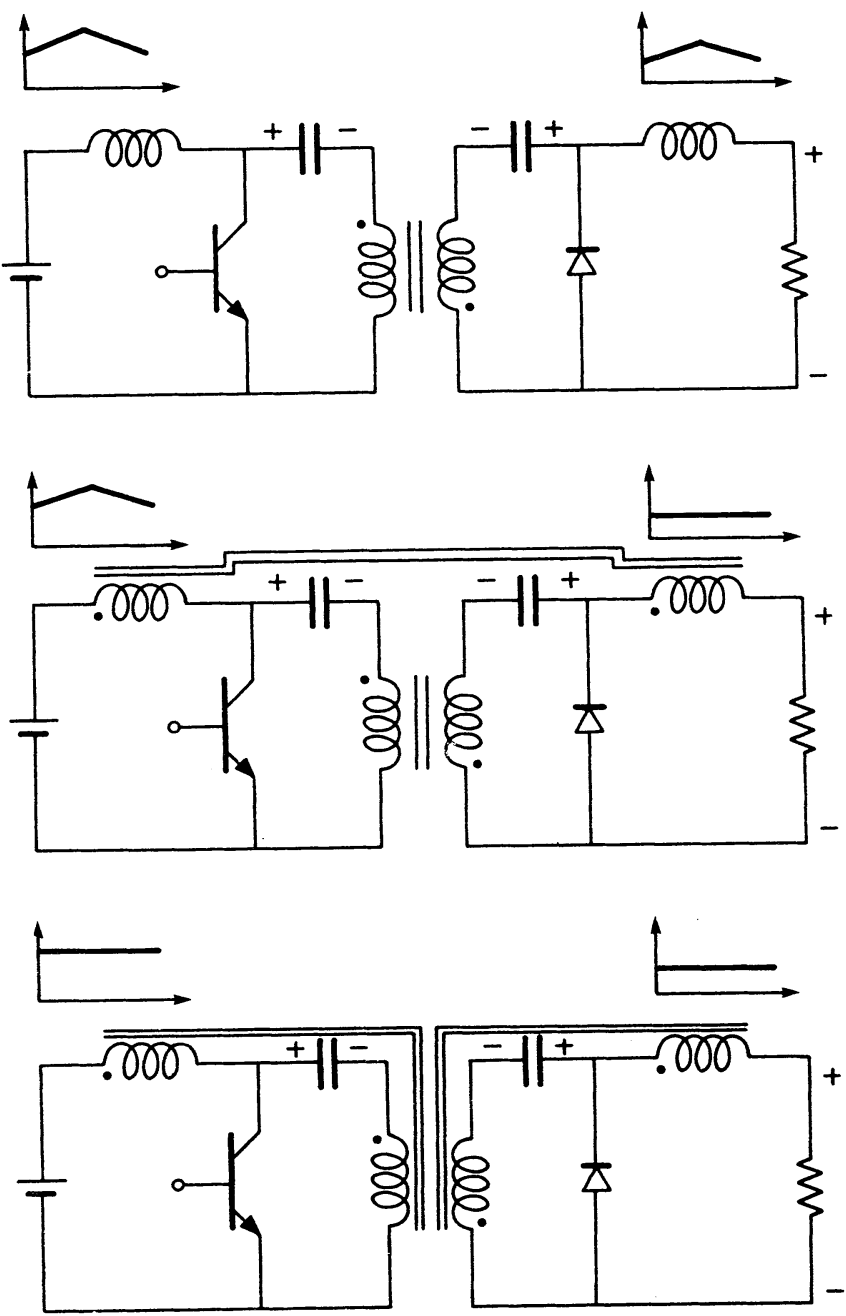

Fig. 29 Evolution of zero-current ripple topologies through nonisolated (a) and isolated (b) versions. 
Finally the crowning achievement of the converter development is its final evolution into a topology which truly emulates the ideally desired electrically controllable dc-to-dc transformer. This ultimate switching dc-to-dc converter configuration possesses both outstanding features, true dc currents at both ports and dc isolation in the simplest possible topology consisting of a single magnetic circuit with four windings, two capacitors and a single switch implemented by usual transistor diode combination. The major cornerstones in the development of the isolated converter configurations are summarized in Fig. 29b.

In summary, a long journey in development of optimum switching converter topologies has been successfully completed: from the conventional buck-boost with large pulsating currents at both input and output ports, through a new converter with both currents nonpulsating to a true dc-to-dc switching converter along both routes featuring nonisolated as well as isolated versions.

\section{CONCLUSION}

A long and very exciting journey into the world of switching dc-to-dc converter topologies initiated several years ago [2] has come to its fruition in establishing a switching hardware realization which truly emulates the ideal dc-to-dc transformer function. After such an exhaustive trip [1-14, 16-19], let us pause for the moment and reminiscence about the major milestones encountered on the road.

The traditional approach taken by many researchers and practicing engineers was indeed very simple: let us get the required dc-to-dc conversion function first by using some simple switching mechanism (such as buck or buck-boost) and then we will cure its problems, such as pulsating input and output currents later. This has even been generalized recently into a theory [20], "which views switching converters as being classified and related by function, not by circuit topology". It attaches the full emphasis on the switching mechanism alone, while the storage components (inductors, capacitors, transformers) are considered only after the fact to "clean up" input and output current or voltage waveforms through additional filtering.

Our approach, however, was just the opposite: from the very beginning we considered that storage and energy transfer elements (inductors, capacitors, transformers), are together with the switches an integral part of the overall problem. Furthermore, we have not only attached extreme importance to converter topologies but with this paper we have extended the previous topology of electrical connections into its complementary topology of magnetic connections through the newly introduced integrated magnetics approach.

A few words now about the switching conversion complexities. At any point in the development, we have introduced the additional complexity by adding elements or new electrical or magnetic connections for only two reasons: a) because it was the simplest way to get the additional feature or function, for example, dc isolation introduction into the basic nonisolated converter or its extension to a four-quadrant bidirectional switching power amplifier; b) as an intermediate step only toward potential further simplification (such as the reduction of the cascaded boost-buck converter into the Cuk converter )

Even when seemingly a very simple configuration was achieved in the basic converter, desire to still further simplify and improve its performance led to the new coupled-inductor concept, which is here generalized into a useful integrated magnetics approach. They now become useful tools for converter improvement, independent of technology. Although component manufacturers will always come up with better and improved components such as transistors, magnetic cores, capacitors, etc., their utilization in different converter topologies may significantly differ. For example, the coupledinductor implementation will result in substantial savings in size, weight and losses when compared with the uncoupled case, regardless of the stateof-the art of magnetic core technology.

Along the development we have strived for the fundamental conceptual solutions. This has been very beneficial in two respects: it not only resulted in the host of new, very useful and practical switching configurations, but also gave birth to some fundamental techniques and methods such as the coupled-inductor concept, the integrated magnetics approach as well as duality theory for switching structures. All these can now be used as tools to improve performance of many other switching configurations.

Finally, dc-to-dc conversion topologies are extended along the same objective to include bidirectional power flow (two quadrant converters) [5] and dc-to-ac inversion and power amplification (four-quadrant converters) [6]. Thus, the approach has been generalized to include the whole spectrum of Power Electronics applications.

\section{REFERENCES}

[1] Slobodan Cuk, "Modelling, Analysis, and Design of Switching Converters," PhD thesis, California Institute of Technology, November 1976. Also, NASA Report CR-135174.

[2] Slobodan Ćuk and R. D. Middlebrook, "A New Optimum Topology Switching Dc-to-Dc Converter," IEEE Power Electronics Specialists Conference, 1977 Record, pp. 160-179 (IEEE Publication 77CH 1213-8 AES).

[3] Slobodan Ćuk and R. D. Middlebrook, "CoupledInductor and Other Extensions of a New Optimum Topology Switching Dc-to-Dc Converter," IEEE Industry Applications Society Annual Meeting, 1977 Record, pp. 1110-1126 (IEEE Publication $77 \mathrm{CH} 1246-8-\mathrm{IA})$. 
[4] R. D. Middlebrook and Slobodan Ćuk, "Isolation and Multiple Output Extensions of a New Optimum Topology Switching Dc-to-Dc Converter," IEEE Power Electronics Specialists Conference 1978 Record, pp. 256-264 (IEEE Publication 78CH1337-5 AES).

[5] R. D. Middlebrook, Slobodan Ćuk, and W. Behen, "A New Battery Charger/Discharger Converter," IEEE Power Electronics Specialists Conference, 1978 Record, pp. 251-255 (IEEE Publication 78CH1337-5 AES).

[6] Slobodan Cuk and Robert W. Erickson, "A Conceptually New High-Frequency Switched-Mode Amplifier Technique Eliminates Current Ripple," Proc. Fifth National Solid-State Power Conversion Conference (Powercon 5), Pp. G3.1-G3.22, May 1978.

[7] Slobodan Cuk, "General Topological Properties of Switching Structures," IEEE Power Electronics Specialists Conference, 1979 Record, pp. 109-130.

[8] Loman Rensink, Art Brown, Shi-Ping Hsu, and Slobodan Ćuk, "Design of a Kilowatt Off-Line Switcher Using a Ćuk Converter," Proc. Sixth National Solid-State Power Conversion Conference (Powercon 6).

[9] Slobodan Ćuk and R. D. Middlebrook, "Advances in Switched-Mode Power Conversion," survey paper, Robotics Age, Winter 1979, Vol. 1, No. 2, pp. 6-19.

[10] Shi-Ping Hsu, "Problems in Analysis and Design of Switching Regulators," PhD thesis, California Institute of Technology, September 1979.

[11] Loman Rensink, "Switching Regulator Configurations and Circuit Realizations," PhD thesis, California Institute of Technology, December 1979 .

[12] G. E. Bloom, and A. Eris, "Practical Design Considerations of a Multi-Output Cuk Converter," IEEE Power Electronics Specialists Conference, 1979 Record, pp. 133-146 (IEEE Publication 79CH1461-3 AES).

[13] G. E. Bloom, A. Eris, and R. Ruble, "Modelling, Analysis, and Design of a Multi-Output Cuk Converter," Proc. Seventh National Solid-State Power Conversion Conference, pp. I1.1-I1.19, March 1980.

[14] G. E. Bloom, A. Eris, "Modelling and Analysis of a Multi-Output Cuk Converter," IEEE Power Electronics Specialists Conference, June 1980, Atlanta, Georgia.

[15] Colonel W. T. McLyman, "Transformer and Inductor Design Handbook," Marcel Dehker, Inc., New York.
[16] Slobodan Cuk and R. D. Middlebrook, "Dc-toDc Switching Converter," U.S. Patent 4,184, 197, January 15, 1980. Foreign patents pending.

[17] Slobodan Cuk, "Push-Pu11 Switching Power Amplifier," U.S. Patent 4,186,437, January 29, 1980. Foreign patents pending.

[18] Slobodan Cuk, "Dc-to-Dc Switching Converter with Zero Input and Output Current Ripple and Integrated Magnetics Circuits," U.S. Patent Application, March 30, 1979.

[19] Slobodan Cuk and R. D. Middlebrook, "Dc-toDc Converter Having Reduced Ripple Without Need for Adjustments," U.S. Patent Application, June 15, 1979.

[20] Peter Wood, "General Theory of Switching Power Converters," IEEE Power Electronics Specialists Conference," 1979 Record, pp. 3-10, (IEEE Publication 79CH1461-3 AES).

[21] Slobodan Ćuk, "Switching Dc-to-Dc Converter with Zero Input or Output Current Ripple," IEEE Industry Applications Society Annual Meeting, 1978 Record, pp. 1131-1146, IEEE 78CH1346-61A.

[22] Hiromitsu Hirayama, "Simplifying Switched Mode Converter Design with a New Variable Leakage Transformer Topology," Proc. Seventh National Solid-State Power Conversion Conference (Powercon 7), pp. E1.1-E1.10, March 1980.

[23] R. P. Masscy and E. C. Snyder, "High-Voltage Single-Ended Dc-Dc Converter," IEEE Power Electronics Specialists Conference, 1977 Record, pp. 156-159.

[24] R. D. Middlebrook, "Modelling and Design of the Ĉk Converter," Proc. Sixth National Solid-State Power Conversion Conference (Powercon 6), pp. G3.1-G3.14, May 1979. 